\title{
1 Bacillus cereus biofilm formation on central venous catheters of hospitalised
}

2 cardiac patients

4 Samman Ikramª, , Adam Heikal 2,*, Sarah Finker,, , Antje Hofgaard ${ }^{\mathrm{c}}$, Yasir Rehman ${ }^{\mathrm{a}}$, $5 \quad$ Anjum Nasim Sabria ${ }^{\mathrm{a}}$ Ole Andreas Økstad ${ }^{\mathrm{b}}$

6

7 a Department of Microbiology \& Molecular Genetics, University of the

$8 \quad$ Punjab, Quaid-e-Azam Campus, Lahore, Pakistan

$9 \quad{ }^{b}$ Centre for Integrative Microbial Evolution and Section for Pharmacology and

10 Pharmaceutical Biosciences, Department of Pharmacy, University of Oslo, PO Box

111068 Blindern, 0316 Oslo, Norway.

12 'Department of Biosciences, University of Oslo, P.O. Box 1066 Blindern, 0316 Oslo,

13 Norway.

14 * These authors contributed equally to the study

15 Corresponding authors: Samman Ikram, samman.phd.mmg@pu.edu.pk; Ole Andreas

16 Økstad, aloechen@farmasi.uio.no 


\section{Abstract}

Formation of bacterial biofilms is a risk with many in situ medical devices. Biofilm-forming Bacillus species are associated with potentially life-threatening catheter-related blood stream infections in immunocompromised patients. Here, bacteria were isolated from biofilm-like structures within the lumen of central venous catheters (CVCs) from two patients admitted to cardiac hospital wards. Isolates belonged to the Bacillus cereus group, exhibited strong biofilm formation propensity, and mapped phylogenetically close to the B. cereus emetic cluster. Together, whole genome sequencing and quantitative PCR confirmed that the isolates constituted the same strain and possessed a range of genes important for and up-regulated during biofilm formation. Antimicrobial susceptibility testing demonstrated resistance to trimethoprimsulphamethoxazole, clindamycin, penicillin and ampicillin. Inspection of the genome revealed several chromosomal $\beta$-lactamase genes and a sulphonamide resistant variant of folP. This study clearly shows that $B$. cereus persisting in hospital ward environments may constitute a risk factor from repeated contamination of CVCs.

Keywords: Biofilm, central venous catheters, cardiac patients, Bacillus cereus group, whole genome sequencing, comparative genomics 
In clinical settings, development of biofilms can promote infection by the persistence

41 of bacteria on medical devices, thereby acting as reservoirs for disease (Bridier et al. 2012). Bacillus cereus is a Gram-positive, facultatively anaerobic, spore-forming bacterium, which is ubiquitous in natural environments and a notorious contaminant of fomites as well as food. Biofilm-forming strains of $B$. cereus have been reported as causing nosocomial bacteraemia following catheter-related infections (Kuroki et al. 2009), and have the potential to cause catheter related blood stream infections (CRBSIs) even in immunocompetent patients (Hernaiz et al. 2003). Known to produce a variety of toxins, $B$. cereus also has the ability to cause two forms of food poisoning, as well as severe conditions such as septicaemia, central nervous system infection and endocarditis in immunocompromised individuals (Bottone 2010, Drobniewski 1993,

51 Lede et al. 2011). The capability of B. cereus to act as a pathogen is largely attributable to the synergistic effects of several virulence factors that cause tissue degradation and resistance to the immune system of the host (Visiello et al. 2016). Among the secreted

54 virulence factors are several haemolysins, three phospholipases (including PI-PLC and 55 PC-PLC), an emesis-inducing toxin (emetic toxin), and three pore-forming enterotoxins; haemolysin BL (HBL), non-haemolytic enterotoxin (NHE), and cytotoxin et al. 2000, Schoeni and Wong 2005, Stenfors Arnesen et al. 2008). Many key genes involved in $B$. cereus group biofilm formation and biofilm regulatory networks have

60 also recently been elucidated (Fagerlund et al. 2014, Fagerlund et al. 2016, Okshevsky 61 et al. 2018, Pflughoeft et al. 2011, Yan et al. 2017). 
64 was isolated twice from central venous catheters (CVCs) of two different cardiac

65 patients admitted to different hospital wards during overlapping time intervals, and an

66 extensive phenotypic and genotypic characterisation of the isolate was carried out.

67 Direct staining of catheters indicated that the isolates were able to produce biofilm in

68 situ, which was confirmed using scanning electron microscopy and a microtitre plate in

69 vitro biofilm formation assay. Whole genome shotgun sequencing (WGS) confirmed

70 that both isolates constituted the same strain, placed the strain in close proximity of the

71 B. cereus emetic strain cluster, and allowed a comparative analysis of genes related to

72 biofilm formation. The characterisation approach in this study represents a

73 comprehensive strategy for studying biofilm forming bacterial strains associated with 74 medical devices.

75

76 
Methods

78

79

80

81

82

83

84

85

86

87

88

89

90

91

92

93

94

95

96

97

98

Blue

Staining of bacteria within central venous catheter (CVC) lumen with Alcian

CVCs used in this study were made from polyurethane (Model No. CVC-3175, Royal Fornia Medical, China) and adherence of bacteria to the CVC lumen walls was visualised using Alcian Blue stain, a cationic dye that stains acidic polysaccharides such as those found in the bacterial cell wall (Nermut and Svobodová 1965). Catheter lumens were locked with the stain solution $(0.1 \%)$ for 10 minutes and then washed three times with phosphate buffer saline (PBS) (Qurashi and Sabri 2012).

\section{Isolation, characterisation and identification of bacteria from central venous} catheters of cardiac patients

Bacterial isolates S1 and S12 were isolated by sampling from CVCs of two cardiac patients, removed on post-operative days 6 and 10, respectively. Bacteria were grown on blood agar (haemolysis) at $37^{\circ} \mathrm{C}$ for 24 hours, followed by biochemical tests (API20E kit, bioMerieux) and 16S rRNA sequencing (PCR amplification using primers 27F: AGAGTTTGATCMTGGCTCAG and 1492R: TACGGYTACCTTGTTACGACTT, and Sanger sequencing using primers 785F: GGATTAGATACCCTGGTA and 907R: CCGTCAATTCMTTTRAGTTT, through Macrogen Inc., Korea). 
99 Fagerlund et al. (Fagerlund et al. 2016), using 96-well round-bottomed polystyrene

100 plates (Nest Biotechnology Co., LTD, China). Culture medium containing planktonic

101 bacterial cells was removed after 24,48 and 72 hours of static incubation at $37^{\circ} \mathrm{C}$ and

102 wells were carefully washed twice with PBS. Biofilm staining was performed with

103 crystal violet $(0.1 \%)$ for 10 minutes at room temperature. After rinsing with water three

104 times, $200 \mu \mathrm{L}$ of $33 \%$ (v/v) glacial acetic acid was added to extract biofilm-bound dye,

105 and absorbance was measured at $550 \mathrm{~nm}$ using a microplate reader (CLARIOstar ${ }^{\circledR}$,

106 BMG LABTECH). Strains were tested in technical duplicates for each experiment and

107 statistical significance determined by one-way ANOVA (Dunn's multiple comparisons

108 test), using GraphPad Prism v7.

109

$110 \quad$ Scanning electron microscopy analysis of biofilm structure

111 Scanning electron microscopy (SEM) was used to analyse cells in B. cereus biofilm.

112 For growth of the biofilm, glass slides $(8 \mathrm{~mm})$ were placed in culture medium and

113 incubated at $37^{\circ} \mathrm{C}$ for 48 hours. Slides were then fixed with $2.5 \%$ glutaraldehyde in

$1140.1 \mathrm{M}$ sodium cacodylate buffer $(\mathrm{pH} 7.4)$ and kept over night at $4{ }^{\circ} \mathrm{C}$. Samples were

115 washed twice in $0.1 \mathrm{M}$ sodium cacodylate buffer $(\mathrm{pH} 7.4)$ for 10 minutes and treated

116 with osmium tetroxide $1.0 \%$ in $0.1 \mathrm{M}$ cacodylate buffer for 1 hour at room temperature

117 post fixation. Washing was repeated three times for 10 minutes in the same buffer.

118 Dehydration was carried out in an ethanol gradient $(50,70,80,90,96,100 \%)$ for 10

119 minutes and four times each in $100 \%$ ethanol for 15 minutes. Dehydrated samples were

120 subsequently critical-point dried using carbon dioxide in a CPD 030 critical-point dryer

121 (Bal-Tec, CA, USA), and mounted on aluminium stubs with 9.0mm carbon adhesive

122 tabs (Electron Microscopy Sciences) prior to sputter coating with 3.5nm platinum in a 
123 Cressington coating system 308R (Cressington Scientific Instruments, UK). A Hitachi

124 S-4800 field emission gun scanning electron microscope was used for the analysis of 125 samples (Hitachi, Japan).

\section{Antibiotic resistance profiling}

127 The antimicrobial susceptibility of the isolates was elucidated using a standard broth

128 microdilution method performed on Sensititre ${ }^{\mathrm{TM}}$ Gram Positive plates GPALL1F

129 (ThermoFisher Scientific). The broth microdilution method was executed according to

130 CLSI guidelines with minor modifications (CLSI 2015). Sensititre ${ }^{\mathrm{TM}}$ plates were

131 inoculated according to instructions given by the manufacturer, with $50 \mu \mathrm{L}$ of $4-6 \times 10^{5}$

$132 \mathrm{CFU} \mathrm{ml}{ }^{-1}$ bacterial suspension per well, and the plates were incubated for 24 hours at

$13337^{\circ} \mathrm{C}$. The $\mathrm{CFU} \mathrm{ml}{ }^{-1}$ of the inoculum was confirmed by serial dilutions on agar plates.

135 Whole genome shotgun sequencing (WGS), genome assembly and

136 bioinformatics analysis

137 Genomic DNA for WGS was prepared from overnight cultures using the MO BIO

138 DNeasy UltraClean Microbial kit (Qiagen, USA) and sequenced using 150 bp paired-

139 end reads on the Illumina HiSeq platform (Illumina Inc., Hayward, CA). To facilitate

140 de novo assembly by reducing computational requirements, 1.0 million reads were

141 randomly sampled from both forward and reverse reads using Seqtk (Shen et al. 2016)

142 De novo assembly was performed using A5-MiSeq (Coil et al. 2015) and annotation

143 was performed using the NCBI Prokaryotic Genome Annotation Pipeline (Tatusova et

144 al. 2016). Draft genomes of Bacillus cereus isolates S1 and S12 were submitted to

145 GenBank under BioProject PRJNA419487 with accession numbers PHHT00000000 
146 and PHHU00000000, respectively. Average nucleotide identity between the two

147 isolates was calculated using the ANI: Average Nucleotide Identity calculator

148 (Rodriguez-R and Konstantinidis 2016). MegaBLAST searches were performed within

149 Geneious version 11.0.5 (Kearse et al. 2012). For comparative genomics analyses, the

150 complete genome of Bacillus thuringiensis strain 407 cry- (accession number

151 NC_018877) (Sheppard et al. 2013) was used.

\section{Multilocus sequence typing (MLST) and phylogenetic tree construction}

153 A phylogenetic tree of the B. cereus group was constructed as reported earlier

154 (Fagerlund et al. 2016) by applying the distance based Neighbour-Joining method 155 BioNJ (Gascuel 1997) on MLST data from seven housekeeping genes using gene 156 sequences extracted from the WGS data. Analyses were performed according to the 157 Tourasse-Helgason MLST scheme (Tourasse et al. 2006) (http://mlstoslo.uio.no). Tree 158 construction was executed using Seaview 4 (Gouy et al. 2010) and tree visualisation 159 was done with Tree Graph 2 (Stover and Muller 2010). Six of the seven major 160 phylogenetic clusters of the B. cereus group (Guinebretiere et al. 2008, Tourasse et al. 161 2011) were represented in the analysis.

162

163 RNA isolation and reverse transcription quantitative PCR (qPCR)

164 To harvest RNA from biofilm cells, B. cereus cells were cultured in $10 \mathrm{~mL}$ of LB 165 medium (Falcon tubes) in three biological replicates (technical duplicates) at $37^{\circ} \mathrm{C}$ in a 166 static incubator. Biofilms were harvested after 48 hours of incubation. Planktonic cells 167 were removed from the culture vial by removing the liquid broth (pipetted out) 168 underneath the floating surface pellicle biofilm. Fresh LB broth was added and the 169 surface pellicle biofilm along with the ring biofilm on the walls of the tube (liquid-air 
170

171

172

173

174

175

176

178

179

180

181

182

183

184

185

186

187

188

189

190

191

192

193

194

interface, scraped off aseptically) were resuspended in the fresh broth, before harvesting by centrifugation. To harvest RNA from planktonic cells, bacterial isolates were grown to exponential phase ( 2.5 hours, $\left.\mathrm{OD}_{600}=1.3\right)$ in $5 \mathrm{~mL}$ LB medium (Falcon tubes) at $37^{\circ} \mathrm{C}, 220 \mathrm{rpm}$, and then added ice-cold methanol (1:1 ratio) prior to harvesting of cells by centrifugation. For extraction of RNA from the planktonic and biofilm cultures, a Precellys 24 Tissue Homogeniser (Bertin) was used for cell lysis, followed by RNA isolation using the RNeasy Mini Kit (Qiagen).

Prior to qPCR, RNA was treated with TURBO DNase (Ambion) and then cleaned using the RNeasy Mini Kit (Qiagen; RNA Cleanup protocol). cDNA synthesis was performed in technical duplicates for each sample, using the High-Capacity cDNA Reverse Transcription Kit (Thermo Fisher Scientific) and random hexamers (Applied Biosystems). Appropriate negative control reactions in which reverse transcriptase enzyme was not added, were included for all RNA samples.

qPCR was performed essentially as previously described (Fagerlund et al. 2016). Briefly, qPCR was performed using the LightCycler 480 Real-Time PCR System (Roche) in 96-well microtiter plates with a final reaction volume of $10 \mu \mathrm{L}$ per well, using $0.1 \mu \mathrm{L}$ cDNA, $0.5 \mu \mathrm{M}$ of each primer, and $5 \mu \mathrm{L}$ of Light Cycler 480 SYBR Green I Master (Roche). The primers used are listed in Supplementary table 1. Three housekeeping genes, gatB/yqeY, rpsU, and $u d p$, were used as reference genes, and were included for each cDNA sample. These genes have previously been shown to be stably expressed throughout the $B$. cereus life cycle, and to be well suited as reference genes in B. cereus qPCR (Reiter et al. 2011). Cycling conditions were as follows: $95^{\circ} \mathrm{C}$ for 5 min followed by 45 cycles at $95^{\circ} \mathrm{C}$ for $10 \mathrm{~s}, 58^{\circ} \mathrm{C}$ for $10 \mathrm{~s}$, and $72^{\circ} \mathrm{C}$ for $8 \mathrm{~s}$. Following the completion of cycling, a melting curve analysis was performed, resulting in a single product specific melting temperature for all samples (single peak). The lack of 
195 amplification in all negative control reactions (no reverse transcriptase added) was used

196 to confirm the absence of amplification of contaminating DNA. The quantification

197 cycle $(C \mathrm{q})$ value for each $\mathrm{qPCR}$ reaction was determined using the second derivative

198 maximum method, employing LightCycler 480 software (Roche).

199 For gene expression analysis, the average of the $C$ q values for the two technical

200 replicates for each sample was transformed into a linear scale expression quantity using

201 the formula $2^{\mathrm{Cq}}$ (Pfaffl 2001). For each target gene in each of the biological replicates,

202 the gene expression was then normalised to the geometric mean of the $2^{C q}$ values

203 obtained for the three reference genes ( $\Delta \mathrm{Cq}$-method). Averages and standard deviations

204 were then calculated from the normalised expression values in the biological triplicates. 
Results

\section{Isolation of bacteria contaminating CVCs of hospitalised patients}

208 Bacteria were isolated from the CVCs of two cardiac patients who had undergone heart

209 surgery, and had been treated with inotropes, anticoagulants (post-operative only) and

210 antibiotics (pre-operative and post-operative) (Supplementary table 2). Whilst inserted

211 in patients, catheters had been flushed with $0.9 \%$ saline each time after administration

212 of intravenous drugs or after drawing blood, and patients did not have symptoms of

213 infection at the time of catheter removal. Staining of CVCs with Alcian Blue clearly

214 revealed the presence of a bacterial biofilm throughout the CVC (Fig. 1), with a total

215 bacterial load described in Supplementary table 3. Altogether nineteen morphologically

216 different colonies were isolated by sampling of the CVCs (Supplementary table 4). Two

217 isolates (S1 and S12) were found to produce large, circular, grey coloured colonies with

218 a zone of haemolysis when grown on blood agar plates.

219 [Figure 1 near here]

221 Identification of bacterial isolates by biochemical characterisation and $16 S$

$222 \quad$ rRNA gene sequencing

223 Using 16S rRNA sequencing, the nineteen morphologically different isolates were

224 found to belong to Bacillus species, both within and outside of the B. cereus group, as 225 well as to Staphylococcus haemolyticus (two isolates) (Supplementary table 4). Isolates

226 S1 and S12 were both characterised biochemically as being citrate-positive, indole227 negative, and positive for gelatin liquification and acid production from D-glucose 228 (Supplementary table 5) (Logan and Berkeley 1984). Furthermore, nucleotide BLAST 
229 searches (Altschul et al. 1990, Altschul et al. 1997) of their respective 16S rDNA 230 sequence toward the NCBI nr/nt database (https://blast.ncbi.nlm.nih.gov/) showed that 231 both isolates belonged to the $B$. cereus group.

232

Genome sequencing of B. cereus isolates S1 and S12

234 Draft genome assembly of the S1 and S12 isolates produced a total of 131 scaffolds $235(\mathrm{~N} 50=3682392)$ for $\mathrm{S} 1$ and 46 scaffolds $(\mathrm{N} 50=2913153)$ for S12. Total draft genome 236 sizes were approximately 5.28 Mbp and 5.23 Mbp for S1 and S12, respectively, both 237 with a mean coverage $>50$, and a $\% \mathrm{GC}$ of 35.5 . Two-way average nucleotide identity 238 (Goris et al. 2007) was $>99.9 \%$ (S.D. 0.1\%) indicating that both isolates were the same 239 strain. Mapping of reads from S12 on to the S1 draft genome assembly produced only 240 four single nucleotide polymorphisms, three of which exerted no protein effect, and one 241 which resulted in a substitution in sphingomyelin phosphodiesterase. An insertion 242 (tandem repeat) was the only other variation between the two isolates identified at 20X 243 coverage or greater, further illustrating the extremely high similarity between the two 244 genomes, and essentially confirming that the two isolates are indeed the same strain. 245 Inspection of the S1 and S12 genomes revealed annotation of CDSs (in both isolates) 246 for a class A $\beta$-lactamase Bla1, a BcII family subclass B1 metallo- $\beta$-lactamase and the 247 folP gene encoding sulphonamide resistance, providing a genetic basis for the antibiotic 248 resistance observed in Table 1.

$250 \quad$ Phylogenetic mapping of B. cereus S1 and S12

251 MLST genes were extracted from the whole genome sequence data set of B. cereus 
252 isolates S1 and S12, employing the modified Tourasse-Helgason scheme (Tourasse et 253 al. 2006), and used to build a distance-based tree, showing that S1 and S12 mapped 254 close to the $B$. cereus emetic cluster, most closely matching the $B$. cereus m1293 strain 255 (Fig. 2). Phylogenetic position and the absence of any cyt, cry, vip, py or emetic toxin 256 genes indicated that the isolates were most likely non-emetic B. cereus. Phylogenetic 257 mapping of S1 and S12 strongly suggested that these organisms are two separate 258 isolates of the same strain. Based on the MLST data and the extremely high similarity 259 between the genome sequences of the two isolates (practically identical) it was 260 concluded that S1 and S12 were indeed the same strain, isolated on two separate 261 occasions (hereafter named B. cereus strain CVC_S1) and chose to focus on CVC_S1 262 for further phenotypic characterisation.

263 [Figure 2 near here]

\section{B. cereus CVC_S1 biofilm formation and structure}

266 A microtitre plate assay for biofilm formation revealed that B. cereus strain CVC_S1 267 had the ability to form biofilm after 24 hours incubation time, with a maximum after 26848 hours (Fig. 3). SEM analysis clearly showed that the isolate formed aggregated 269 communities (Fig. 4), further demonstrating that biofilm formation is an integral 270 characteristic of strains that colonise semi-invasive medical devices.

$271 \quad$ [Figures 3 and 4 near here]

273 Antimicrobial susceptibility of B. cereus CVC_S1

274 Antimicrobial susceptibility testing using the SensiTitre ${ }^{\mathrm{TM}}$ microbroth dilution method 
275 showed that the CVC_S1 strain was resistant to trimethoprim/sulfamethoxazole, 276 oxacillin, ampicillin and penicillin, and intermediate to clindamycin, employing CLSI 277 guideline M45 (CLSI 2016) (Table 1).

278 [Table 1 near here]

\section{Comparative genomics of B. cereus CVC_S1 with other B. cereus group}

$281 \quad$ strains

282 The size of B. cereus CVC_S1 (5.28 Mb; 5,702 CDS) and CVC_S12 (5.23 Mbp; 5,607

283 CDS) genomes was in good agreement with previously sequenced $B$. cereus group 284 reference strains. Although being closely related to emetic strains, the isolates did not 285 map inside the emetic cluster (Fig. 2), and accordingly did not carry the emetic toxin 286 plasmid (pXO1 family plasmid) nor genes specifying enzymes known to produce this 287 toxin. Also, sequence similarity searches (BLAST) did not detect an ortholog to the 288 pXO1 plasmid family replication gene, repX.

The proficiency with which B. cereus CVC_S1 formed biofilms, both in situ on

290 CVCs and in the in vitro microplate assays, led us to investigate the presence / absence 291 of genes known to be important in Bacillus sp. biofilm formation (Caro-Astorga et al. 292 2014, Fagerlund et al. 2014, Fagerlund et al. 2016, Gao et al. 2015, Gelis-Jeanvoine et 293 al. 2017, Okshevsky et al. 2018, Rasko et al. 2004). Coding sequences for genes linked 294 to biofilm formation were extracted from the complete genomes of reference strains 295 Bacillus thuringiensis 407 cry- (B. cereus group biofilm reference strain; accession 296 number NC_018877), B. cereus ATCC 14579 (B. cereus type strain, accession numbers 297 AE016877 and AE016878) or B. cereus ATCC 10987 (accession numbers AE017194 298 and AE017195), and a megaBLAST search was performed against the B. cereus 
299 CVC_S1 draft genome. Orthologs showing $75-95 \%$ pairwise identity $(96-100 \%$ 300 query coverage) were identified for almost all key biofilm-formation genes 301 investigated, including those encoding key biofilm transcriptional regulators, matrix 302 structural genes (matrix protein, putative matrix polysaccharide), potential extracellular 303 DNA synthesis genes, and cyclic-di-GMP metabolism genes (Table 2), in line with the 304 strong biofilm-forming properties of the isolates. However, the genome sequence of 305 neither isolate (S1, S12) carried genes for the lipopeptide kurstakin (Gelis-Jeanvoine et 306 al. 2017) nor the cyclic-di-GMP responsive effector protein BspA (Sudarsan et al. 2008, 307 Tang et al. 2016). Interestingly, delineation of the $B$. cereus CVC_S1 accessory genome 308 relative to its closest neighbours (B. cereus $\mathrm{m} 1293$ and the $B$. cereus emetic reference 309 strain F4810/72 [AH187]) as well as to the B. thuringiensis Bt407 cry- reference strain, 310 revealed that the CVC_S1 isolate contained the following unique CDS with predicted 311 functions that may indicate a potential involvement in biofilm formation; a unique 312 DegU-like transcriptional regulatory protein, a putative antitoxin HigA2, and a second 313 copy of: i) a putative Autoinducer 2 sensor kinase/phosphatase LuxQ (luxQ_2) and ii) 314 a biofilm operon icaADBC HTH-type negative transcriptional regulator IcaR.

\section{5 [Table 2 near here]}

\section{Expression analysis of conserved biofilm-related genes}

318 In order to investigate the functional role of conserved biofilm-related genes in the $B$. 319 cereus CVC strain S1, a qPCR analysis was performed to compare gene expression in 320 biofilms of $B$. cereus S1 relative to planktonic growing cells of the same strain. 321 Amongst the genes analysed, sinI, encoding an antagonist of the SinR biofilm repressor, 322 was the most strongly upregulated gene in CVC_S1 biofilm ( 7x upregulation), while 323 the $\sin R$ transcriptional repressor ( 3.6x) itself, as well as the tas $A$ amyloid-like protein 
$324(\sim 2.2 \mathrm{x})$ were both induced in biofilm relative to planktonic growth (Fig. 5).

325 Furthermore, galU, encoding a putative polysaccharide synthesis protein, was down-

326 regulated in biofilm, while for genes encoding cyclic-di-GMP metabolising proteins,

$327 c d g F$ and $c d g E$ were both down-regulated in biofilm, while $c d g D$ was up-regulated.

328 [Figure 5 near here] 
329

\section{Discussion}

In addition to its role as a common food-borne pathogen, B. cereus has the potential to cause serious infections in immunocompromised individuals (reviewed in (Bottone 2010, Drobniewski 1993)). In immunocompetent patients, catheter-related blood stream infections have also been described. Typically patients recover upon catheter removal and antibiotic therapy, however fatal outcomes have been reported (Lede et al. 2011). Key members of the B. cereus group, including B. cereus, B. thuringiensis and B. anthracis, have been shown to be efficient biofilm formers, in lab models (Lebeaux et al. 2013), ex vivo on dental equipment (Majed et al. 2016) and on invasive medical devices (Wright 2016). In this study, the same strain of Bacillus cereus was isolated twice (CVC_S1 and CVC_S12), from central venous catheters of two cardiac patients admitted to two adjacent wards within a large surgical intensive care unit of a cardiac hospital. B. cereus CVC_S1 (and CVC_S12) mapped within the phylogenetic cluster harbouring most of the $B$. cereus group clinical isolates (Cluster III), and close to the cluster of emetic strains known to have the potential to cause critical human infections (Dierick et al. 2005, Naranjo et al. 2011). However, similar to other non-emetic nearneighbours to the emetic cluster, such as B. cereus Q1 (Xiong et al. 2009), B. cereus CVC_S1 (and CVC_S12) did not carry the emetic gene cluster, nor the emetic plasmid pCER270, and thus does not constitute an emetic strain. Within the B. cereus group (B. cereus sensu lato), adaptation to various environments and hosts results in the formation of ecotypes within major phylogenetic lineages (Guinebretiere et al. 2008, Fiedoruk et al. 2017). Although the CVC_S1 and CVC_S12 isolates map close to the Q1 strain and the clonal emetic strains (ST26), these strains are however isolated from widely diverse sources, emetic strains frequently isolated from cases of food poisoning, 
353 and Q1 being an environmental strain isolated from a deep sea oil reservoir (Xiong et 354 al. 2009).

The CVC_S1 strain showed resistance to $\beta$-lactam antibiotics (ampicillin, 356 penicillin and oxacillin), related to the presence of several $\beta$-lactamases carried on the 357 chromosome (Luna et al. 2007, Torkar and Bedenic 2018), a diagnostic feature used to 358 separate B. cereus from B. anthracis (Bottone 2010, Chen et al. 2004, Turnbull et al. 359 2004). Moreover, resistance to trimetophrim-sulphametoxasole may be explained by 360 the presence of the folP gene encoding a conserved dihydropteroate synthase, which 361 provides intrinsic sulfonamide resistance in B. anthracis (Valderas et al. 2007). Genes 362 encoding the lipopeptide kurstakin have been shown to be important for biofilm 363 structure (Gelis-Jeanvoin et al. 2017), and the cyclic-di-GMP responsive effector 364 protein BspA (an MSCRAMM family adhesion protein), which is regulated through a 365 c-di-GMP responsive riboswitch, has been suggested to affect biofilm formation 366 (Sudarsan et al. 2016). Neither kurstakin nor BspA are however encoded in the 367 CVC_S1 (or CVC_S12) isolate, showing that these factors are not essential for catheter368 related in situ B. cereus biofilm formation in the hospital environment. qPCR analysis 369 did however show that key biofilm genes such as $\sin I, \sin R$, and $\operatorname{tas} A$ (Fagerlund et al. 370 2014), which are conserved among different B. cereus group strains, including the 371 CVC_S1 and CVC_S12 isolates described here, follow the same 372 transcriptional regulation pattern during biofilm growth in the B. cereus CVC isolate 373 (CVC_S1 strain) as in the model laboratory strain of B. thuringiensis (strain 407 cry-, 374 originally isolated from insect larvae). The qPCR analyses also confirmed that $c d g F$, 375 which is known to encode a diguanylate cyclase (c-di-GMP synthesising enzyme) 376 essential for formation of biofilms in oxygenated environments, similar to what was 377 previously shown in B. thuringiensis (Fagerlund et al. 2016), is transcriptionally down- 
378 regulated in biofilm also in B. cereus. This would again be in line with a model for c379 di-GMP metabolising enzymes being mainly post-transcriptionally controlled and/or 380 controlled through spatial localisation in the cell, as previously suggested (Fagerlund et 381 al. 2016). Importantly, trends in relative expression during biofilm versus planktonic 382 growth for all of the three $c d g$ genes included here $(c d g D, c d g E, c d g F)$ were in 383 accordance with the previous analyses in the reference strain B. thuringiensis 407 cry384 (Fagerlund et al. 2016).

Recent publications, such as that from Tamburini and co-workers (Tamburini 386 et al. 2018), highlight the importance of using powerful genomic tools such as WGS 387 for strain tracking and more precise identification of the origins of BSIs, in order for 388 hospitals and health care providers to most effectively work to prevent infections. Here 389 WGS was used successfully as a predictive tool for the antimicrobial resistance profile 390 of the B. cereus CVC_S1 strain. Also, it is anticipated that the findings presented here 391 will facilitate future investigations into the identification and dissemination of Bacillus 392 spp. as nosocomial pathogens. The isolation of the same B. cereus strain, from CVCs 393 of two patients in two different wards within an overlapping time period, points to $B$. 394 cereus successfully colonising CVCs used in critically ill patients, constituting a 395 potential source of serious bloodstream infections. Herein, the CVC colonising strain 396 has been extensively characterised by biochemical profiling, phylogenetic mapping, 397 biofilm structure and formation propensity, antibiotic resistance profiling, and whole 398 genome sequencing - allowing this isolate to constitute a reference strain for further 399 work on B. cereus group isolates contaminating surfaces in hospital environments and 400 thereby comprising a considerable risk factor for severe nosocomial infections. 401 Previously, B. cereus has often been regarded as an environmental contaminant in 402 clinical samples. However, the repeated isolation of B. cereus from the CVCs of cardiac 
403 patients in this study, together with its known biofilm- and spore-formation capabilities,

404 as well as the results from a recent longitudinal study of the epidemiology of B. cereus

405 infections in French hospitals (Glasset et al. 2018), all point towards B. cereus

406 constituting a true nosocomial pathogen of importance to human health.

407

408 Acknowledgements

409 The authors thank Ewa Jaroszewicz and Beata Urbanczyk Mohebi for excellent

410 experimental assistance. The sequencing service was provided by the Norwegian

411 Sequencing Centre (www.sequencing.uio.no), a national technology platform hosted

412 by the University of Oslo and supported by the 'Functional Genomics' and

413 'Infrastructure' programs of the Research Council of Norway and the Southeastern

414 Regional Health Authorities. This work was supported through a grant to SI from the

415 Higher Education Commission of Pakistan under the International Research Support

416 Initiative Program (reference number No. 1-8/HEC/HRD/2017/6878). AH, SF and

$417 \mathrm{OA} \varnothing$ were supported by the Centre for Integrative Microbial Evolution and the School

418 of Pharmacy, Faculty of Mathematics and Natural Sciences, University of Oslo. 
References

421 Altschul SF, Gish W, Miller W, Myers EW, Lipman DJ. 1990. Basic local alignment

422 search tool. J Mol Biol. Oct 5;215:403-410. Epub 1990/10/05.

423 Altschul SF, Madden TL, Schaffer AA, Zhang J, Zhang Z, Miller W, Lipman DJ. 1997.

424 Gapped BLAST and PSI-BLAST: a new generation of protein database search

425 programs. Nucleic Acids Res. Sep 1;25:3389-3402. Epub 1997/09/01.

426 Bottone EJ. 2010. Bacillus cereus, a volatile human pathogen. Clin Microbiol Rev.

427 Apr;23:382-398. Epub 2010/04/09.

428 Bridier A, Sanchez-Vizuete Mdel P, Le Coq D, Aymerich S, Meylheuc T, Maillard JY,

429 Thomas V, Dubois-Brissonnet F, Briandet R. 2012. Biofilms of a Bacillus subtilis

430 hospital isolate protect Staphylococcus aureus from biocide action. PLoS

431 One.7:e44506. Epub 2012/09/14.

432 Caro-Astorga J, Perez-Garcia A, de Vicente A, Romero D. 2014. A genomic region

433 involved in the formation of adhesin fibers in Bacillus cereus biofilms. Front

434 Microbiol.5:745. Epub 2015/01/30.

435 Chen Y, Tenover FC, Koehler TM. 2004. Beta-lactamase gene expression in a

436 penicillin-resistant Bacillus anthracis strain. Antimicrob Agents Chemother.

437 Dec;48:4873-4877. Epub 2004/11/25.

438 CLSI. 2015. Methods for Dilution Antimicrobial Susceptibility Testing for Bacteria

439 That Grow Aerobically; Approved Standard. CLSI document M07-A10. 10th ed.

440 CLSI. 2016. Methods for Antimicrobial Dilution and Disk Susceptibility Testing of

441 Infrequently Isolated or Fastidious Bacteria. CLSI guideline M45. 3rd ed. 
442 Coil D, Jospin G, Darling AE. 2015. A5-miseq: an updated pipeline to assemble

443 microbial genomes from Illumina MiSeq data. Bioinformatics. Feb 15;31:587-589.

444 Epub 2014/10/24.

445 Dierick K, Van Coillie E, Swiecicka I, Meyfroidt G, Devlieger H, Meulemans A,

446 Hoedemaekers G, Fourie L, Heyndrickx M, Mahillon J. 2005. Fatal family outbreak of

447 Bacillus cereus-associated food poisoning. J Clin Microbiol. Aug;43:4277-4279. Epub

$448 \quad 2005 / 08 / 06$

449 Drobniewski FA. 1993. Bacillus cereus and related species. Clin Microbiol Rev.

450 Oct;6:324-338. Epub 1993/10/01.

451 Ehling-Schulz M, Frenzel E, Gohar M. 2015. Food-bacteria interplay:

452 pathometabolism of emetic Bacillus cereus. Front Microbiol.6:704. Epub

$4532015 / 08 / 04$.

454 Fagerlund A, Dubois T, Okstad OA, Verplaetse E, Gilois N, Bennaceur I, Perchat S,

455 Gominet $M$, Aymerich S, Kolsto AB, et al. 2014. SinR controls enterotoxin expression

456 in Bacillus thuringiensis biofilms. PLoS One.9:e87532.

457 Fagerlund A, Smith V, Rohr AK, Lindback T, Parmer MP, Andersson KK, Reubsaet L,

458 Okstad OA. 2016. Cyclic diguanylate regulation of Bacillus cereus group biofilm

459 formation. Mol Microbiol. Aug;101:471-494.

460 Fiedoruk K, Drewnowska JM, Daniluk T, Leszczynska K, Iwaniuk P, Swiecicka I. 2017.

461 Ribosomal background of the Bacillus cereus group thermotypes. Scientific

462 Reports.7:46430.

463 Gao T, Foulston L, Chai Y, Wang Q, Losick R. 2015. Alternative modes of biofilm

464 formation by plant-associated Bacillus cereus. Microbiologyopen. Jun;4:452-464.

465 Epub 2015/04/02. 
466 Gascuel O. 1997. BIONJ: an improved version of the NJ algorithm based on a simple 467 model of sequence data. Mol Biol Evol. Jul;14:685-695. Epub 1997/07/01.

468 Gelis-Jeanvoine S, Canette A, Gohar M, Caradec T, Lemy C, Gominet M, Jacques P, 469 Lereclus D, Slamti L. 2017. Genetic and functional analyses of krs, a locus encoding 470 kurstakin, a lipopeptide produced by Bacillus thuringiensis. Research in microbiology. 471 May;168:356-368. Epub 2016/06/30.

472 Glasset B, Herbin S, Granier SA, Cavalie L, Lafeuille E, Guerin C, Ruimy R, Casagrande473 Magne F, Levast M, Chautemps N, et al. 2018. Bacillus cereus, a serious cause of 474 nosocomial infections: Epidemiologic and genetic survey. PLoS One.13:e0194346. 475 Epub 2018/05/24.

476 Gohar M, Faegri K, Perchat S, Ravnum S, Okstad OA, Gominet M, Kolsto AB, Lereclus 477 D. 2008. The PlcR virulence regulon of Bacillus cereus. PLoS One. Jul 30;3:e2793. 478 Epub 2008/07/31.

479 Goris J, Konstantinidis KT, Klappenbach JA, Coenye T, Vandamme P, Tiedje JM. 2007. 480 DNA-DNA hybridization values and their relationship to whole-genome sequence 481 similarities. Int J Syst Evol Microbiol. Jan;57:81-91. Epub 2007/01/16.

482 Gouy M, Guindon S, Gascuel O. 2010. SeaView version 4: A multiplatform graphical 483 user interface for sequence alignment and phylogenetic tree building. Mol Biol Evol. 484 Feb;27:221-224. Epub 2009/10/27.

485 Guinebretiere MH, Thompson FL, Sorokin A, Normand P, Dawyndt P, Ehling-Schulz

$486 M$, Svensson B, Sanchis V, Nguyen-The C, Heyndrickx M, et al. 2008. Ecological 487 diversification in the Bacillus cereus Group. Environ Microbiol. Apr;10:851-865. Epub $488 \quad 2007 / 11 / 27$ 
489 Hernaiz C, Picardo A, Alos JI, Gomez-Garces JL. 2003. Nosocomial bacteremia and

490 catheter infection by Bacillus cereus in an immunocompetent patient. Clin Microbiol

491 Infect. Sep;9:973-975. Epub 2003/11/18.

492 Kearse M, Moir R, Wilson A, Stones-Havas S, Cheung M, Sturrock S, Buxton S, Cooper

493 A, Markowitz S, Duran C, et al. 2012. Geneious Basic: an integrated and extendable

494 desktop software platform for the organization and analysis of sequence data.

495 Bioinformatics. Jun 15;28:1647-1649. Epub 2012/05/01.

496 Kotiranta A, Lounatmaa K, Haapasalo M. 2000. Epidemiology and pathogenesis of

497 Bacillus cereus infections. Microbes Infect. Feb;2:189-198. Epub 2000/04/01.

498 Kuroki R, Kawakami K, Qin L, Kaji C, Watanabe K, Kimura Y, Ishiguro C, Tanimura S,

499 Tsuchiya Y, Hamaguchi I, et al. 2009. Nosocomial bacteremia caused by biofilm-

500 forming Bacillus cereus and Bacillus thuringiensis. Intern Med.48:791-796. Epub

$501 \quad 2009 / 05 / 16$

502 Lebeaux D, Chauhan A, Rendueles O, Beloin C. 2013. From in vitro to in vivo Models

503 of Bacterial Biofilm-Related Infections. Pathogens. May 13;2:288-356. Epub

504 2013/01/01.

505 Lede I, Vlaar A, Roosendaal R, Geerlings S, Spanjaard L. 2011. Fatal outcome of

506 Bacillus cereus septicaemia. Neth J Med. Nov-Dec;69:514-516. Epub 2011/12/17.

507 Logan NA, Berkeley RC. 1984. Identification of Bacillus strains using the API system. J

508 Gen Microbiol. Jul;130:1871-1882. Epub 1984/07/01.

509 Luna VA, King DS, Gulledge J, Cannons AC, Amuso PT, Cattani J. 2007. Susceptibility

510 of Bacillus anthracis, Bacillus cereus, Bacillus mycoides, Bacillus pseudomycoides and

511 Bacillus thuringiensis to 24 antimicrobials using Sensititre automated microbroth 
512 dilution and Etest agar gradient diffusion methods. J Antimicrob Chemother.

513 Sep;60:555-567. Epub 2007/06/26.

514 Majed R, Faille C, Kallassy M, Gohar M. 2016. Bacillus cereus Biofilms-Same, Only

515 Different. Front Microbiol.7:1054. Epub 2016/07/28.

516 Naranjo M, Denayer S, Botteldoorn N, Delbrassinne L, Veys J, Waegenaere J, Sirtaine

517 N, Driesen RB, Sipido KR, Mahillon J, et al. 2011. Sudden death of a young adult

518 associated with Bacillus cereus food poisoning. J Clin Microbiol. Dec;49:4379-4381.

519 Epub 2011/10/21.

520 Nermut MV, Svobodová V. 1965. Alcian Blue staining of bacterial cell walls.

521 Zeitschrift für Allgemeine Mikrobiologie.5:378-385.

522 Okshevsky M, Louw MG, Lamela EO, Nilsson M, Tolker-Nielsen T, Meyer RL. 2018. A

523 transposon mutant library of Bacillus cereus ATCC 10987 reveals novel genes

524 required for biofilm formation and implicates motility as an important factor for

525 pellicle-biofilm formation. Microbiologyopen. Apr;7:e00552. Epub 2017/11/23.

526 Pfaffl MW. 2001. A new mathematical model for relative quantification in real-time

527 RT-PCR. Nucleic Acids Res. May 1;29:e45. Epub 2001/05/09.

528 Pflughoeft KJ, Sumby P, Koehler TM. 2011. Bacillus anthracis sin locus and regulation

529 of secreted proteases. J Bacteriol. Feb;193:631-639. Epub 2010/12/07.

530 Qurashi AW, Sabri AN. 2012. Biofilm formation in moderately halophilic bacteria is

531 influenced by varying salinity levels. J Basic Microbiol. Oct;52:566-572. Epub

$532 \quad 2011 / 12 / 07$

533 Rasko DA, Ravel J, Okstad OA, Helgason E, Cer RZ, Jiang L, Shores KA, Fouts DE,

534 Tourasse NJ, Angiuoli SV, et al. 2004. The genome sequence of Bacillus cereus ATCC 
53510987 reveals metabolic adaptations and a large plasmid related to Bacillus anthracis

536 pXO1. Nucleic Acids Res.32:977-988. Epub 2004/02/13.

537 Reiter L, Kolsto AB, Piehler AP. 2011. Reference genes for quantitative, reverse-

538 transcription PCR in Bacillus cereus group strains throughout the bacterial life cycle. J

539 Microbiol Methods. Aug;86:210-217. Epub 2011/05/31.

540 Rodriguez-R LM, Konstantinidis KT. 2016. The enveomics collection: a toolbox for

541 specialized analyses of microbial genomes and metagenomes. PeerJ Preprints.

542 Schoeni JL, Wong AC. 2005. Bacillus cereus food poisoning and its toxins. J Food Prot.

543 Mar;68:636-648. Epub 2005/03/18.

544 Shen W, Le S, Li Y, Hu F. 2016. SeqKit: A Cross-Platform and Ultrafast Toolkit for

545 FASTA/Q File Manipulation. PLoS One.11:e0163962. Epub 2016/10/06.

546 Sheppard AE, Poehlein A, Rosenstiel P, Liesegang H, Schulenburg H. 2013. Complete

547 Genome Sequence of Bacillus thuringiensis Strain 407 Cry. Genome Announc. Jan;1.

548 Stenfors Arnesen LP, Fagerlund A, Granum PE. 2008. From soil to gut: Bacillus cereus

549 and its food poisoning toxins. FEMS Microbiol Rev. Jul;32:579-606.

550 Stover BC, Muller KF. 2010. TreeGraph 2: combining and visualizing evidence from

551 different phylogenetic analyses. BMC Bioinformatics. Jan 5;11:7. Epub 2010/01/07.

552 Sudarsan N, Lee ER, Weinberg Z, Moy RH, Kim JN, Link KH, Breaker RR. 2008.

553 Riboswitches in eubacteria sense the second messenger cyclic di-GMP. Science. Jul

$554 \quad 18 ; 321: 411-413$.

555 Tamburini FB, Andermann TM, Tkachenko E, Senchyna F, Banaei N, Bhatt AS. 2018.

556 Precision Identification of Diverse Bloodstream Pathogens from the Gut Microbiome.

557 bioRxiv.310441. 
558 Tang Q, Yin K, Qian H, Zhao Y, Wang W, Chou SH, Fu Y, He J. 2016. Cyclic di-GMP

559 contributes to adaption and virulence of Bacillus thuringiensis through a riboswitch-

560 regulated collagen adhesion protein. Sci Rep. Jul 06;6:28807.

561 Tatusova T, DiCuccio M, Badretdin A, Chetvernin V, Nawrocki EP, Zaslavsky L,

562 Lomsadze A, Pruitt KD, Borodovsky M, Ostell J. 2016. NCBI prokaryotic genome

563 annotation pipeline. Nucleic Acids Res. Aug 19;44:6614-6624. Epub 2016/06/28.

564 Torkar KG, Bedenic B. 2018. Antimicrobial susceptibility and characterization of

565 metallo-beta-lactamases, extended-spectrum beta-lactamases, and carbapenemases

566 of Bacillus cereus isolates. Microb Pathog. Mar 16;118:140-145. Epub 2018/03/20.

567 Tourasse NJ, Helgason E, Klevan A, Sylvestre P, Moya M, Haustant M, Okstad OA,

568 Fouet A, Mock M, Kolsto AB. 2011. Extended and global phylogenetic view of the

569 Bacillus cereus group population by combination of MLST, AFLP, and MLEE

570 genotyping data. Food Microbiol. Apr;28:236-244. Epub 2011/02/15.

571 Tourasse NJ, Helgason E, Okstad OA, Hegna IK, Kolsto AB. 2006. The Bacillus cereus

572 group: novel aspects of population structure and genome dynamics. J Appl

573 Microbiol. Sep;101:579-593. Epub 2006/08/16.

574 Turnbull PC, Sirianni NM, LeBron Cl, Samaan MN, Sutton FN, Reyes AE, Peruski LF, Jr.

575 2004. MICs of selected antibiotics for Bacillus anthracis, Bacillus cereus, Bacillus

576 thuringiensis, and Bacillus mycoides from a range of clinical and environmental

577 sources as determined by the Etest. J Clin Microbiol. Aug;42:3626-3634. Epub

$578 \quad 2004 / 08 / 07$

579 Valderas MW, Bourne PC, Barrow WW. 2007. Genetic basis for sulfonamide

580 resistance in Bacillus anthracis. Microb Drug Resist. Spring;13:11-20. Epub

$5812007 / 06 / 01$ 
582 Visiello R, Colombo S, Carretto E. 2016. Bacillus cereus Hemolysins and Other

583 Virulence Factors, In The Diverse Faces of Bacillus cereus: Academic Press.

584 Wright WF. 2016. Central Venous Access Device-Related Bacillus Cereus

585 Endocarditis: A Case Report and Review of the Literature. Clin Med Res. Jun;14:109-

586 115. Epub 2016/05/28.

587 Xiong Z, Jiang Y, Qi D, Lu H, Yang F, Yang J, Chen L, Sun L, Xu X, Xue Y, et al. 2009.

588 Complete genome sequence of the extremophilic Bacillus cereus strain Q1 with

589 industrial applications. Journal of bacteriology.191:1120-1121. Epub 2008/12/05.

590 Yan F, Yu Y, Gozzi K, Chen Y, Guo JH, Chai Y. 2017. Genome-Wide Investigation of

591 Biofilm Formation in Bacillus cereus. Appl Environ Microbiol. Jul 1;83. Epub

$592 \quad 2017 / 04 / 23$

593

594 
Table 1. Susceptibility of B. cereus CVC_S1 to antimicrobials using the Sensititre ${ }^{\mathrm{TM}}$ microbroth dilution method. For interpretation of MIC values, breakpoints from the CLSI guideline M45 (CLSI 2016) were used. S: susceptible, I: intermediate, R: resistant, NS: nonsusceptible. ${ }^{a}$ According to interpretative criteria for Staphylococcus spp. from the CLSI

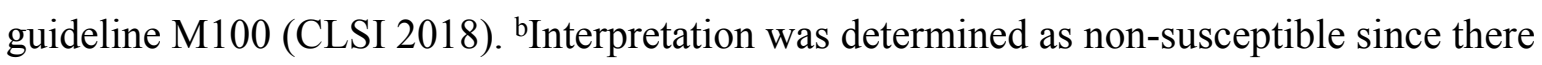
only is a breakpoint set for susceptible. ${ }^{\mathrm{c} A c c o r d i n g}$ to interpretative criteria for Staphylococcus spp. from the (EUCAST 2018). ${ }^{\mathrm{d}}$ No interpretation available.

Chloramphenicol

Daptomycin

Gentamicin

Linezolid

Rifampin

Trimethoprim/sulfamethoxazole

Quinupristin/dalfopristin

Tetracycline

Erythromycin

Oxacillin

Ampicillin

Penicillin

Vancomycin

Levofloxacin

Tigecycline

Moxifloxacin

Clindamycin

Streptomycin

Ciprofloxacin

Nitrofurantoin

$$
\text { MIC (mg L-1) Interpretation }
$$

\begin{tabular}{cc}
\hline 8 & $\mathrm{~S}$ \\
$>4$ & $\mathrm{NS}^{\mathrm{ab}}$ \\
$\leq 2$ & $\mathrm{~S}$ \\
2 & $\mathrm{~S}^{\mathrm{a}}$
\end{tabular}

$\leq 0.5 \quad \mathrm{~S}$

$>4 / 76 \quad \mathrm{R}$

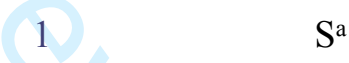

$\leq 2 \quad \mathrm{~S}$

$\leq 0.25 \bigcirc \mathrm{S}$

$2 \quad \mathrm{R}^{\mathrm{a}}$

1

$\mathrm{R}$

2

$\mathrm{R}$

2

S

0.5

S

$0.06 \quad \mathrm{~S}^{\mathrm{c}}$

$\leq 0.25 \quad \mathrm{~S}^{\mathrm{a}}$

$\leq 1000$

$\leq 1 \quad \mathrm{~S}$

$\leq 32 \quad \mathrm{~S}^{\mathrm{a}}$ 
Biofouling

Page 30 of 48

$$
\begin{aligned}
& 1 \\
& \begin{array}{l}
2 \\
3
\end{array} \\
& 4 \\
& 5 \\
& 6 \\
& 7 \\
& 8 \\
& 9 \\
& 10 \\
& 11 \\
& 12 \\
& 13 \\
& 14 \\
& 15 \\
& 16 \\
& 17 \\
& 18 \\
& 19 \\
& 20 \\
& 21 \\
& 22 \\
& 23 \\
& 24 \\
& 25 \\
& 26 \\
& 27 \\
& 28 \\
& 29 \\
& 30 \\
& 31 \\
& 32 \\
& 33 \\
& 34 \\
& 35 \\
& 36 \\
& 37 \\
& 38 \\
& 39 \\
& 40 \\
& 41 \\
& 42 \\
& 43 \\
& 44 \\
& 45 \\
& 46 \\
& 47 \\
& 48 \\
& 49 \\
& 50 \\
& 51 \\
& 52 \\
& 53 \\
& 54 \\
& 55 \\
& 56 \\
& 57 \\
& 58 \\
& 59 \\
& 60
\end{aligned}
$$

http://mc.manuscriptcentral.com/gbif 
Table 2. MegaBLAST analyses identifying genes in B. cereus CVC_S1 with the highest sequence identity to experimentally identified biofilm-related genes from the B. thuringiensis 407 cry- and B. cereus ATCC 10987, both fully sequenced biofilm model strains from the B. cereus group. For the rightmost column, a star indicates the reference is the same as the one immediately above in the table. Bt 407 - B. thuringiensis 407; BC 14579 - B. cereus ATCC $14579 ; B C$ 10987 - B. cereus ATCC 10987.

\begin{tabular}{|c|c|c|c|c|c|c|c|}
\hline Gene/function & Locus tag & Organism & Protein product & $\begin{array}{l}\text { Identity } \\
(\%)\end{array}$ & $\begin{array}{c}\text { Coverage } \\
(\%)\end{array}$ & BcS1 locus tag & Reference \\
\hline \multicolumn{8}{|l|}{ Regulators } \\
\hline spoOA & BTB_RS21200 & Bt 407 & Sporulation transcription factor & 93 & 100 & CV717_17110 & $\begin{array}{l}\text { (Fagerlund } \\
\text { et al. 2014) }\end{array}$ \\
\hline $\operatorname{sinl}$ & BTB_RS06545 & Bt 407 & DNA-binding anti-repressor & 92 & 100 & CV717_02990 & $*$ \\
\hline $\sin R$ & BTB_RS06540 & Bt 407 & Transcriptional regulator & 95 & 100 & CV717_02985 & $*$ \\
\hline $\operatorname{cod} Y$ & BTB_RS19405 & Bt 407 & $\begin{array}{l}\text { GTP-sensing pleiotropic } \\
\text { transcriptional regulator }\end{array}$ & & 100 & CV717_15285 & $\begin{array}{l}\text { (Lindback } \\
\text { et al. 2012) }\end{array}$ \\
\hline plcR & BTB_RS27305 & Bt 407 & XRE family transcriptional regulator & 90 & 99 & CV717_20790 & $\begin{array}{l}\text { (Hsueh et } \\
\text { al. 2006) }\end{array}$ \\
\hline$n p r R$ & BTB_RS03040 & Bt 407 & Transcriptional regulator & 77 & 93 & CV717_23020 & $\begin{array}{l}\text { (Verplaetse } \\
\text { et al. 2015) }\end{array}$ \\
\hline$a b r B$ & BTB_RS00215 & Bt 407 & $\begin{array}{c}\text { AbrB/MazE/SpoVT family DNA- } \\
\text { binding domain-containing protein }\end{array}$ & 97 & 100 & CV717_27350 & $\begin{array}{l}\text { (Fagerlund } \\
\text { et al. 2014) }\end{array}$ \\
\hline \multicolumn{8}{|c|}{ Matrix protein encoding genes } \\
\hline caly & BTB_RS06535 & Bt 407 & $\begin{array}{l}\text { Biofilm extracellular matrix fibre } \\
\text { protein and cell surface adhesin }\end{array}$ & 95 & 100 & CV717_02980 & $\begin{array}{c}\text { (Caro- } \\
\text { Astorga et } \\
\text { al. 2014) }\end{array}$ \\
\hline
\end{tabular}


Amyloid-like structural fibre

the extracellular biofilm matrix

$\begin{array}{ccccccc}\text { sipW } & \text { BTB_RS06520 } & \text { Bt } 407 & \text { Signal peptidase I } & 91 & 100 & \text { CV717_02965 } \\ \text { bc_1280 } & \text { BTB_RS06530 } & \text { Bt } 407 & \text { DUF4047 domain-containing } & 73 & 98 & \text { CV717_02975 }\end{array}$

Putative matrix polysaccharide synthesis genes

\begin{tabular}{|c|c|c|c|c|c|c|c|}
\hline lytR & BC5265 & Bc 14579 & $\begin{array}{l}\text { LytR family transcriptional } \\
\text { regulator }\end{array}$ & 84 & 100 & CV717_21245 & $\begin{array}{l}\text { (Ivanova et } \\
\text { al. 2003) }\end{array}$ \\
\hline galU & BTB_RS26920 & Bt 407 & $\begin{array}{l}\text { UTP--glucose-1-phosphate } \\
\text { uridylyltransferase }\end{array}$ & 88 & 99 & CV717_21200 & $\begin{array}{l}\text { (Sheppard } \\
\text { et al. 2013) }\end{array}$ \\
\hline gtaB2 & BC_5275 & Bc 14579 & $\begin{array}{l}\text { UTP--glucose-1-phosphate } \\
\text { uridylyltransferase }\end{array}$ & 88 & 97 & CV717_21200 & $\begin{array}{l}\text { (Ivanova et } \\
\text { al. 2003) }\end{array}$ \\
\hline glycosyl transferase & BCE_5356 & Bc 10987 & $\begin{array}{l}\text { Glycosyl transferase domain } \\
\text { protein, putative }\end{array}$ & 98 & 100 & CV717_21395 & $\begin{array}{l}\text { (Rasko et } \\
\text { al. 2004) }\end{array}$ \\
\hline ugd & BCE_5385 & Bc 10987 & UDP-glucose 6-dehydrogenase & 67 & 57 & CV717_21230 & $*$ \\
\hline $\begin{array}{l}\text { polysaccharide } \\
\text { transport }\end{array}$ & BCE_5386 & Bc 10987 & $\begin{array}{c}\text { Polysaccharide transport protein, } \\
\text { putative }\end{array}$ & 81 & 3 & CV717_21810 & $*$ \\
\hline $\begin{array}{c}\text { capsular } \\
\text { exopolysaccharide } \\
\end{array}$ & BCE_5398 & Bc 10987 & $\begin{array}{c}\text { Capsular exopolysaccharide family } \\
\text { protein }\end{array}$ & 89 & 99 & CV717_21185 & * \\
\hline \multicolumn{8}{|l|}{ eDNA synthesis genes } \\
\hline purA & BC_5468 & Bc 14579 & Adenylosuccinate synthetase & 96 & 100 & CV717_20155 & $\begin{array}{l}\text { (Vilain et } \\
\text { al. 2009) }\end{array}$ \\
\hline purC & BC_0326 & Bc 14579 & $\begin{array}{l}\text { Phosphoribosylaminoimidazole } \\
\text { succinocarboxamide synthetase }\end{array}$ & 99 & 100 & CV717_23470 & $*$ \\
\hline purL & BC_0329 & Bc 14579 & $\begin{array}{l}\text { Phosphoribosylformylglycinamidine } \\
\text { synthetase }\end{array}$ & 94 & 100 & CV717_23485 & $*$ \\
\hline
\end{tabular}




\begin{tabular}{|c|c|c|c|c|c|c|c|}
\hline krsE & BC_2450 & Bc 14579 & Macrolide-efflux protein & 82 & 3 & CV717_26600 & $\begin{array}{c}\text { (Gelis- } \\
\text { Jeanvoine } \\
\text { et al. 2017) }\end{array}$ \\
\hline krsA & BC_2452 & Bc 14579 & Peptide synthetase & 65 & 27 & CV717_08300 & $*$ \\
\hline$k r s B$ & BC_2453 & BC 14579 & Peptide synthetase & 68 & 6 & CV717_08300 & $*$ \\
\hline$k r s C$ & BC_2456 & Bc 14579 & Peptide synthetase & 65 & 4 & CV717_08300 & * \\
\hline \multicolumn{8}{|c|}{ c-di-GMP metabolism genes } \\
\hline$c d g F$ & BTB_RS03185 & Bt 407 & GGDEF domain-containing protein & 91 & 100 & CV717_22875 & $\begin{array}{l}\text { (Fagerlund } \\
\text { et al. 2016) }\end{array}$ \\
\hline$c d g D$ & BTB_RS27060 & Bt 407 & diguanylate cyclase & 88 & 100 & CV717_21055 & $*$ \\
\hline$c d g E$ & BTB_RS18755 & Bt 407 & $\begin{array}{l}\text { sensor domain-containing } \\
\text { phosphodiesterase }\end{array}$ & 93 & 100 & CV717_14835 & $*$ \\
\hline $\operatorname{cdg} B$ & BTB_RS20530 & Bt 407 & GGDEF domain-containing protein & 89 & 100 & CV717_16430 & $*$ \\
\hline$c d g G$ & BTB_RS17620 & Bt 407 & phosphodiesterase & 68 & 93 & CV717_14835 & $*$ \\
\hline$c d g J$ & BTB_RS20255 & Bt 407 & diguanylate phosphodiesterase & 94 & 100 & CV717_16120 & $*$ \\
\hline \multicolumn{8}{|c|}{ c-di-GMP effectors } \\
\hline bspA (cap) & BC_1060 & Bc 14579 & $\begin{array}{l}\text { MSCRAMM family adhesion } \\
\text { protein }\end{array}$ & 63 & 4 & CV717_00935 & $\begin{array}{l}\text { (Tang et al. } \\
\text { 2016) }\end{array}$ \\
\hline
\end{tabular}




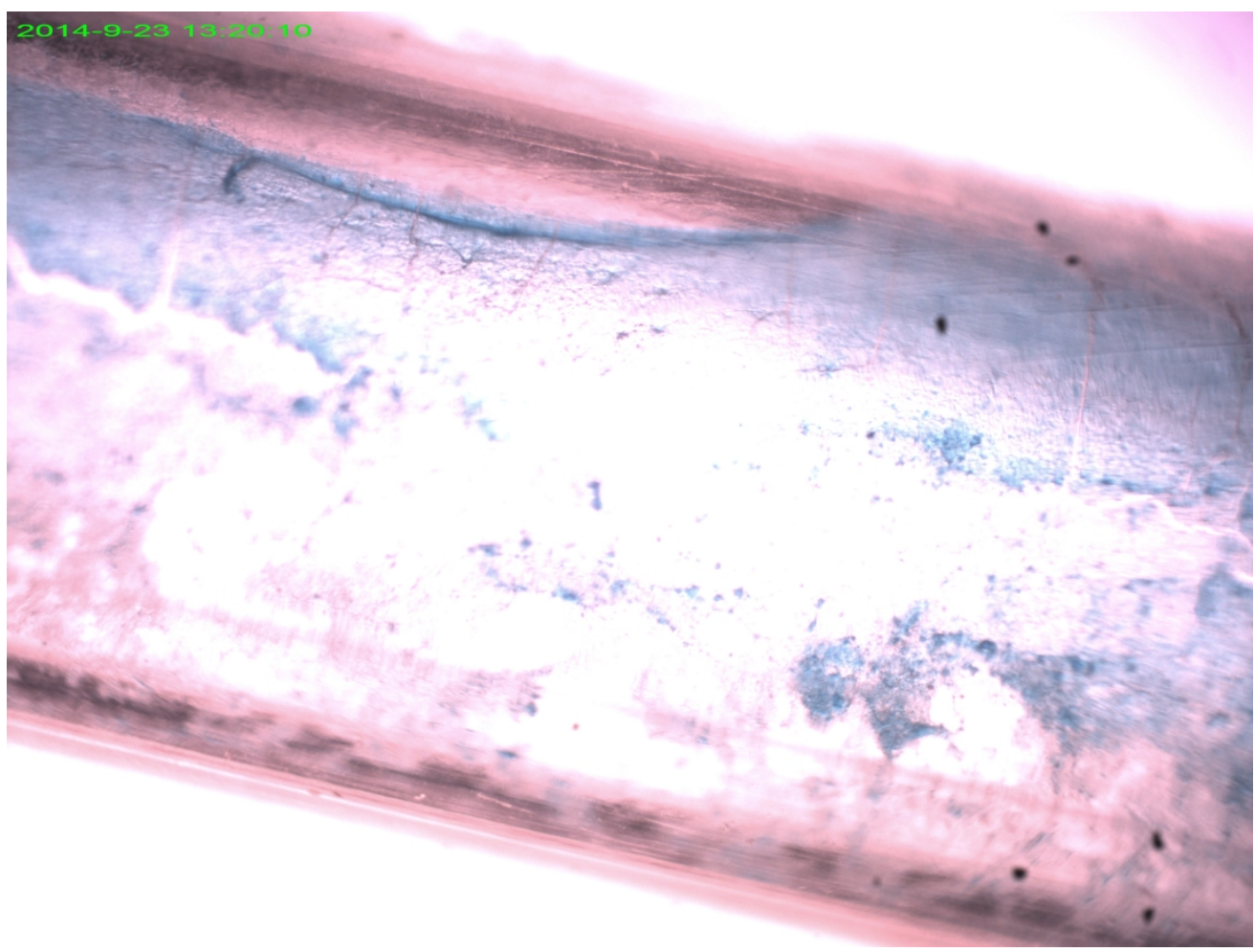

$1881 \times 2468 \mathrm{~mm}(35 \times 20$ DPI $)$ 


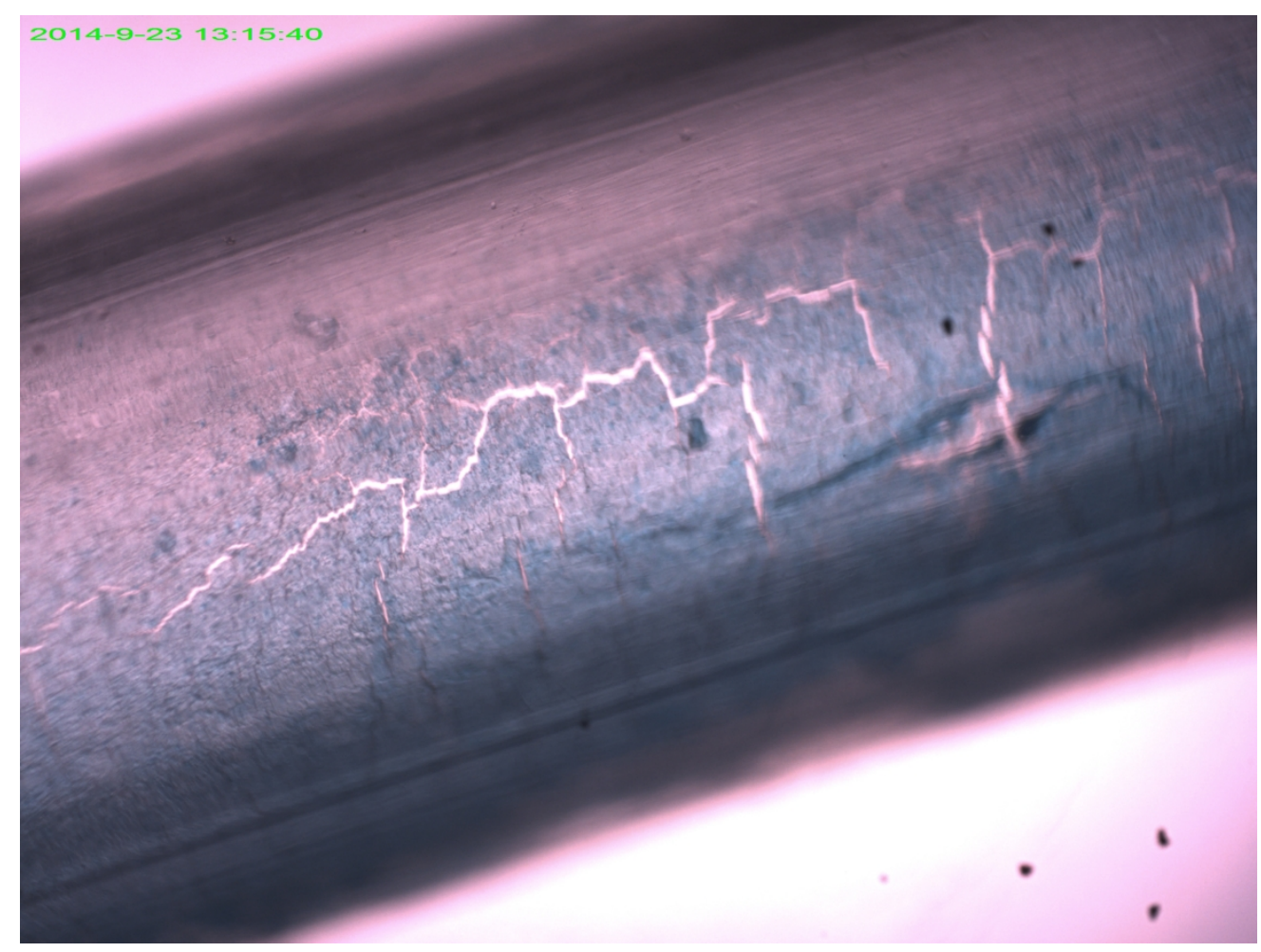

$1881 \times 2468 \mathrm{~mm}(35 \times 20$ DPI $)$ 


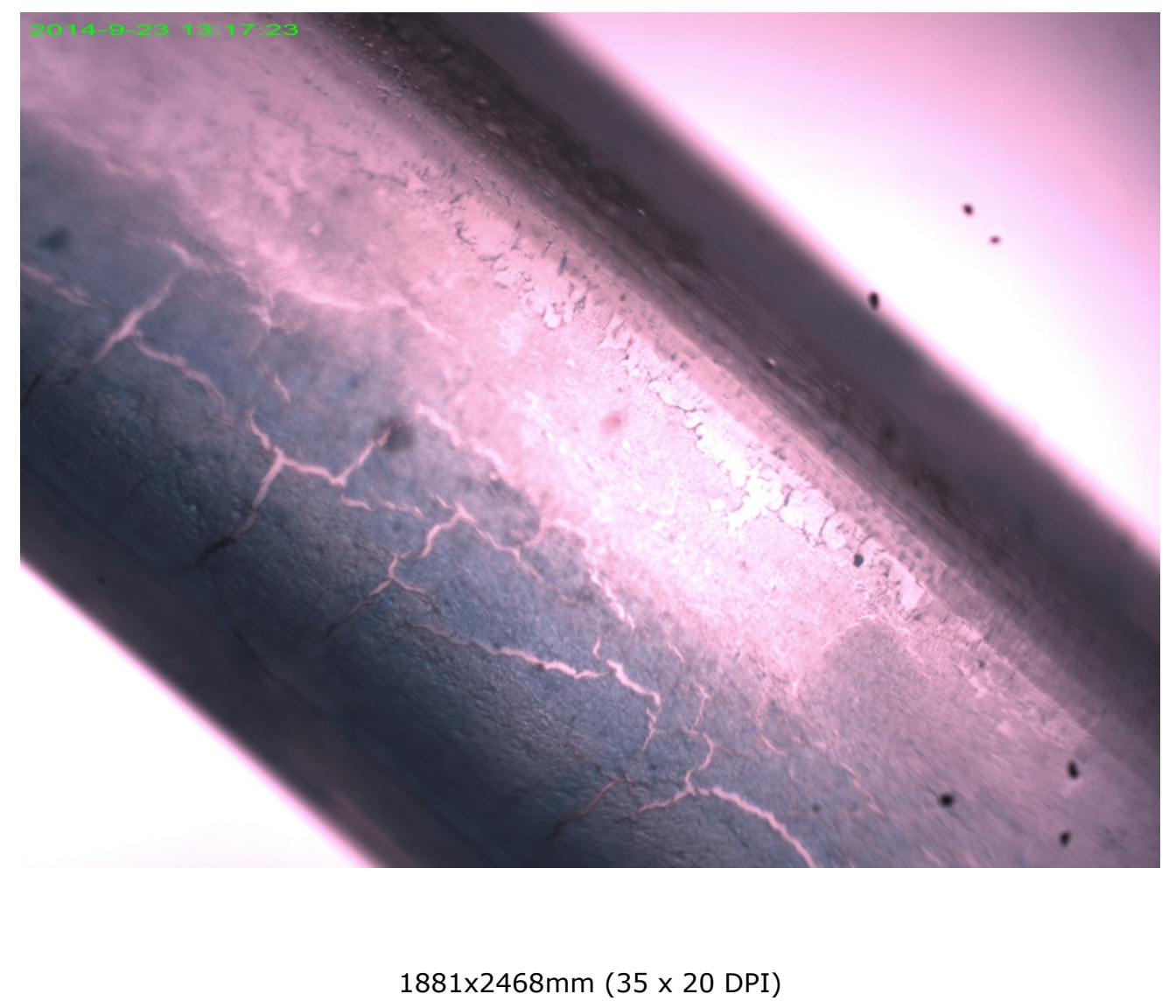

$1881 \times 2468 \mathrm{~mm}(35 \times 20$ DPI $)$ 


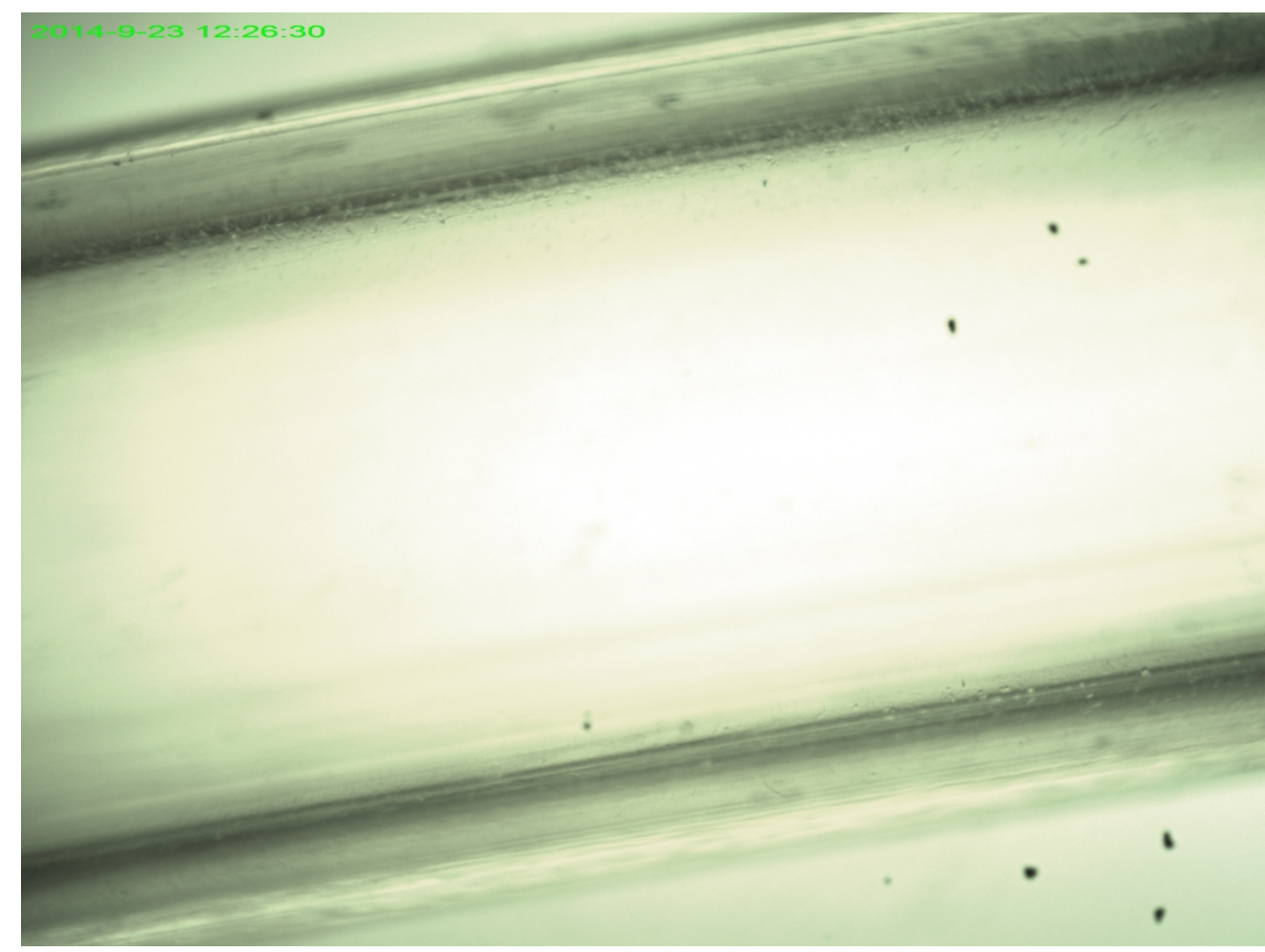

$1881 \times 2468 \mathrm{~mm}(35 \times 20$ DPI) 


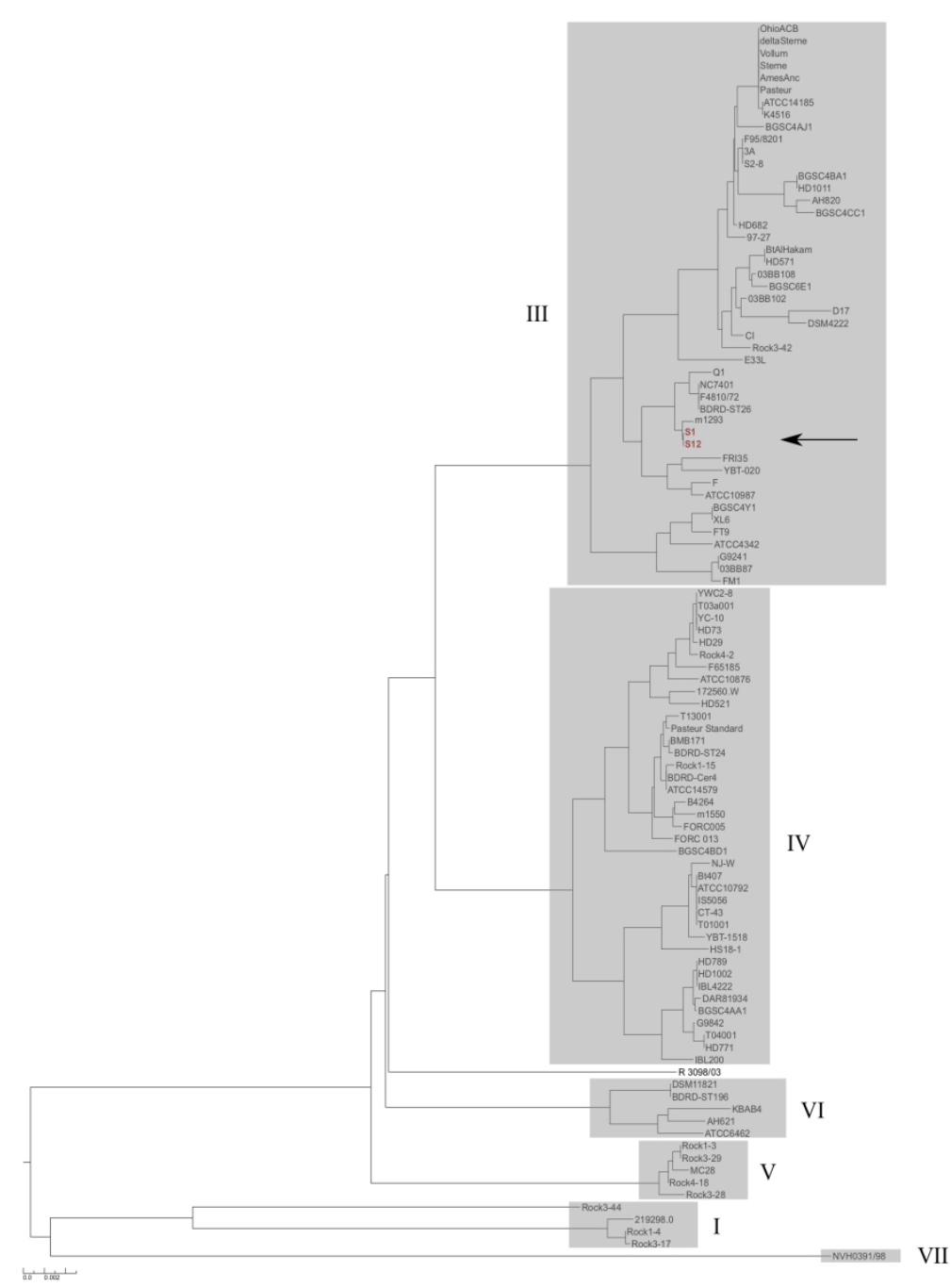

$209 \times 297 \mathrm{~mm}(300 \times 300 \mathrm{DPI})$ 


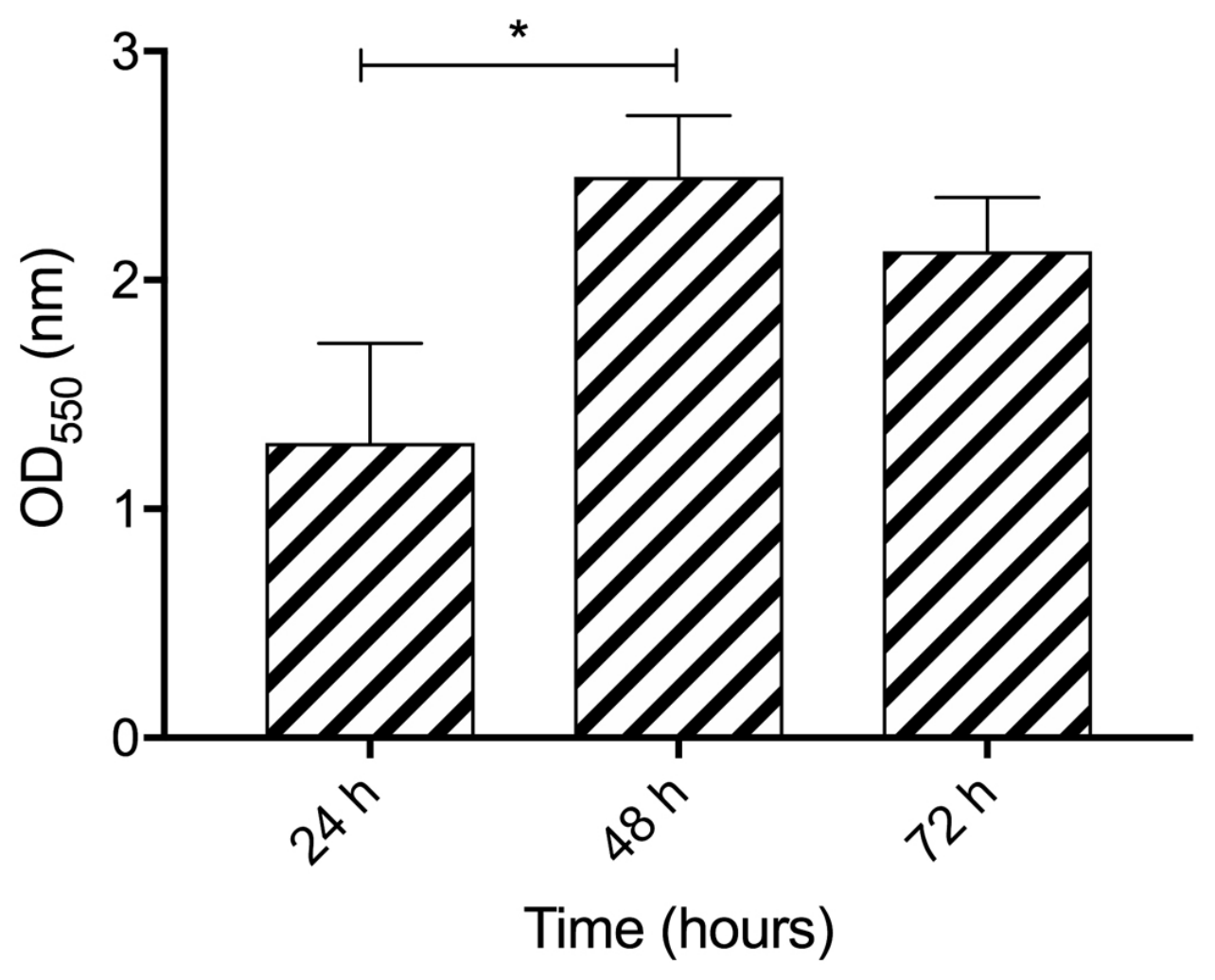

$91 \times 74 \mathrm{~mm}(300 \times 300$ DPI $)$ 


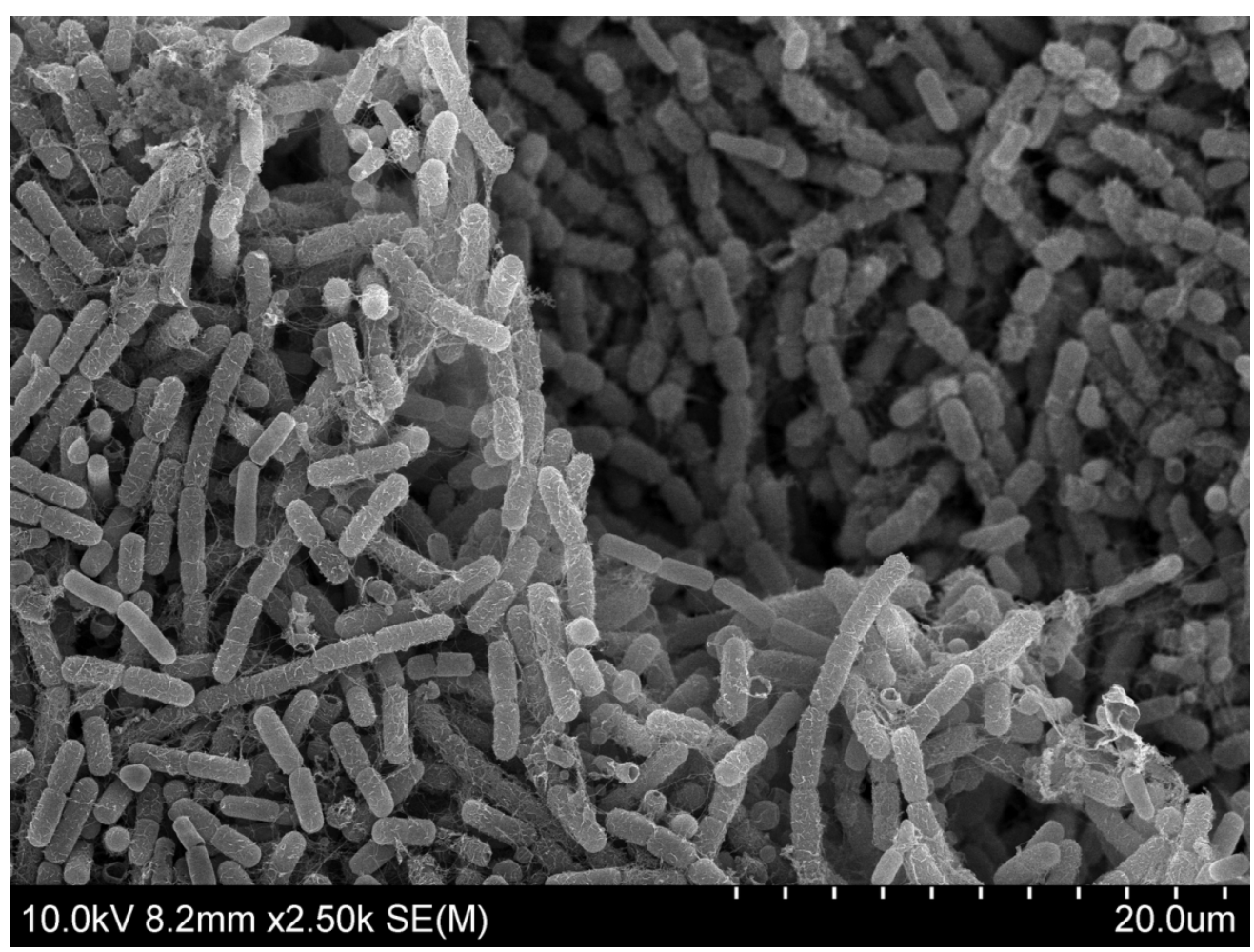

$127 \times 95 \mathrm{~mm}(300 \times 300 \mathrm{DPI})$ 


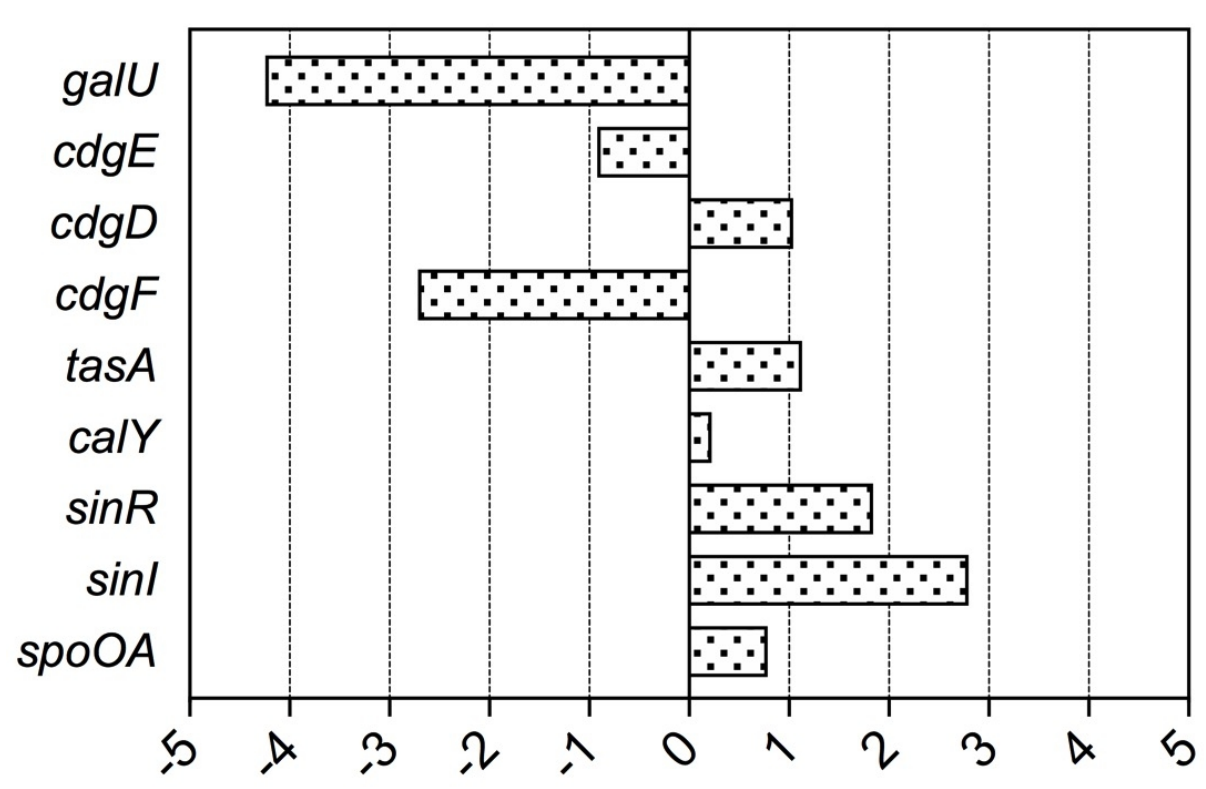

$99 \times 60 \mathrm{~mm}(300 \times 300$ DPI $)$ 


\section{$1 \quad$ Figure captions}

2

3 Figure 1: Alcian Blue stained proximal lumen of CVC from patient 1. (A) Near port. (B) Mid 4 lumen. (C) Near manifold. (D) Control (CVC, not used).

5

6 Figure 2. Positioning of $B$. cereus isolates S1 and S12 (marked with arrow) within a

7 phylogenetic tree representative of the $B$. cereus group, by MLST analysis using seven

8 housekeeping genes. The tree was constructed as described (Methods section). Six of the

9 main phylogenetic clusters (I, III to VII) within the B. cereus group are indicated (grey). The

$10 \mathrm{~S} 1$ and S12 isolates mapped close to the emetic cluster, represented by the B. cereus emetic

11 type strain (F4810/72), B. cereus BDRD-ST26 and B. cereus NC7401.

Figure 3. Biofilm formation of B. cereus CVC_S1 in a microtiter plate assay after 24 hours, 14 48 hours and 72 hours of incubation. Bars constitute the mean of background-subtracted 16

Figure 5. Differentially regulated genes in biofilm growth relative to planktonic growth of $B$. cereus CVC_S1. The bar plots show $\log _{2}$ ratios of gene expression in biofilm cells relative to planktonic cells, as determined by quantitative PCR. Bars extending to the right: genes upregulated in biofilm cells, bars extending to the left: genes upregulated in planktonic cells. 
Supplementary table 1. Sequences of primers used in qPCR analyses.

\begin{tabular}{|c|c|}
\hline Gene & Primer sequence ( $F$, forward; $R$, reverse) \\
\hline \multirow[t]{2}{*}{ SpoOA } & F- TCCACTGCCATCTTTCCGATC \\
\hline & R-AGCAGGCACACCAATTTCATG \\
\hline \multirow[t]{2}{*}{ calY } & F-AATTGGTGGAGGAACATTCGC \\
\hline & R-AAGCGTTGTAGGGTCTAATGTAAG \\
\hline \multirow[t]{2}{*}{$\sin l$} & F- AGACTGACGCATTGGATCAAGA \\
\hline & R- ATTGAGCCTGGCTTGATGGT \\
\hline \multirow[t]{2}{*}{$\sin R$} & F- TGCAGCAGTTCTACAAATTCCAG \\
\hline & R- TTGCATCTTTAACGAGTTGTGTCC \\
\hline \multirow[t]{2}{*}{$\operatorname{tas} A$} & F- GCAGTATTAGGAGCAGCGTTAG \\
\hline & R- CTAAATCAAGCGTACCAGCCG \\
\hline \multirow[t]{2}{*}{$c d g D$} & F- GTAGCAGCCATGAACGAACC \\
\hline & R-ACGGATCTTCACCTGCTTCAG \\
\hline \multirow[t]{2}{*}{$c d g E$} & F- CCGATTGCAGAAGAAACGCTAC \\
\hline & R- GTGAATATCCGCTTGTGTGCC \\
\hline \multirow[t]{2}{*}{$c d g F$} & F- TGTGCTCATATCCGCAAGATG \\
\hline & R- CACGCTGCATTTCTTCCCTG \\
\hline \multirow[t]{2}{*}{ galU } & F- CGACGAAAGCAATGCCGAAA \\
\hline & R-ACGCTTTCCCTTTCCAGTCA \\
\hline \multirow[t]{2}{*}{$u d p$} & F- ACTAGAGAAACTTGGAAATGATCG \\
\hline & R- GACGCTTAATTGCACGGAAC \\
\hline \multirow[t]{2}{*}{ gatB } & F- AGCTGGTCGTGAAGACCTTG \\
\hline & R- CGGCATAACAGCAGTCATCA \\
\hline \multirow[t]{2}{*}{ rpsU } & F-AAGATCGGTTTCTAAAACTGGTACA \\
\hline & R-TTTCTTGCCGCTTCAGATTT \\
\hline
\end{tabular}


Supplementary Table 2. Patient background.

\begin{tabular}{|c|c|c|}
\hline & Patient 1 & Patient 2 \\
\hline Age & 57 & 22 \\
\hline Sex & $\mathrm{F}$ & $\mathrm{F}$ \\
\hline Diagnosis & TVD (Tripple vessel disease) & MR (Mitral Regurgitation) \\
\hline Procedure & $\begin{array}{l}\text { CABG (Coronary Artery } \\
\text { Bypass Grafting) }\end{array}$ & MVR (Mitral Valve Repair) \\
\hline Treatment & $\begin{array}{l}\text { Tab; Ascard 75mg q.d, NoClot } \\
\text { 75mg q.d, (Anti-coagulants) } \\
\text { Losic 20mg } \\
\text { IV; Vancomycin 500mg t.i.d (1 } \\
\text { shot Pre-Op + Post-Op), Zinacef } \\
\text { 750mg t.i.d (Post-Op) } \\
\text { Adrenalin, Dopamin, } \\
\text { Noradrenalin, Lipofundin, } \\
\text { Nephrostril (q.d) }\end{array}$ & $\begin{array}{l}\text { Tab; Ascard 75mg q.d, NoClot } \\
\text { 75mg q.d (Anti-coagulants) } \\
\text { IV; Zinacef 1.5gm (1 shot Pre- } \\
\text { Op) 750mg t.i.d (Post-Op), } \\
\text { Targocid 400mg q.d (Post-Op) } \\
\text { Adrenalin, Dopamin, } \\
\text { Noradrenalin, Lipofundin, } \\
\text { Aminovel }\end{array}$ \\
\hline Length of catheter insertion & 6 days & 10 Days \\
\hline Isolate & CVCS1 & CVCS12 \\
\hline
\end{tabular}


Supplementary table 3. Bacterial load, given in colony forming units (CFU) per $\mathrm{mL}$, for each sample (CVC1-CVC6) from central venous catheters of hospital admitted patients, and specification of the bacterial isolate(s) from each respective sample. DOI described the duration of catheter insertion (in days). Bacterial isolates taken from each sample were selected based on colony morphology.

\begin{tabular}{|l|l|l|l|r|r|l|}
\hline & \multicolumn{3}{|l|}{ CFU $\mathbf{~ m L}^{-\mathbf{1}}$} & & \\
\hline Sample & $\begin{array}{l}\text { DOI (Days } \\
\text { of } \\
\text { Insertion) }\end{array}$ & $\mathbf{1 0}^{\mathbf{0}}$ & $\mathbf{1 0}^{\mathbf{- 1}}$ & $\mathbf{1 0}^{\mathbf{- 2}}$ & $\mathbf{1 0}^{\mathbf{- 3}}$ & $\begin{array}{l}\text { Bacterial isolates from } \\
\text { sample }\end{array}$ \\
\hline CVC 1 & 6 & 110000 & 30000 & 0 & 0 & S1, S2, S3, S4 \\
\hline CVC 2 & 6 & 160000 & 110000 & 40000 & 0 & S5, S6, S7, S8 \\
\hline CVC 3 & 3 & 40000 & 0 & 0 & 0 & S9 \\
\hline CVC 4 & 10 & 330000 & 160000 & 130000 & 10000 & S10, S11, S12, S13, S14, S15 \\
\hline CVC 5 & 4 & 60000 & 10000 & 0 & 0 & S16, S17 \\
\hline CVC 6 & 8 & 190000 & 80000 & 30000 & 0 & S18, S19 \\
\hline
\end{tabular}


Supplementary table 4. Bacterial isolate number, identified organism (species name) and source of isolation, for the 19 bacterial strains isolated from central venous catheters in the present study.

\begin{tabular}{|l|l|l|}
\hline $\begin{array}{l}\text { Bacterial } \\
\text { isolate }\end{array}$ & Identified organism (species name) & Source \\
\hline S1 & Bacillus cereus & CVC Lumens \\
\hline S2 & Bacillus subtilis & CVC Lumens \\
\hline S3 & Bacillus subtilis & CVC Lumens \\
\hline S4 & Staphylococcus haemolyticus & CVC Tip \\
\hline S5 & Bacillus subtilis & CVC Lumens \\
\hline S6 & Bacillus tequilensis & CVC Lumens \\
\hline S7 & Bacillus tequilensis & CVC Lumens \\
\hline S8 & Staphylococcus haemolyticus & CVC Tip \\
\hline S9 & Bacillus subtilis & CVC Lumens \\
\hline S10 & Bacillus subtilis & CVC Lumens \\
\hline S11 & Bacillus subtilis & CVC Lumens \\
\hline S12 & Bacillus cereus & CVC Lumens \\
\hline S13 & Bacillus sp. & CVC Lumens \\
\hline S14 & Bacillus aryabhattai & CVC Lumens \\
\hline S15 & Bacillus subtilis & CVC Lumens \\
\hline S16 & Bacillus subtilis & CVC Lumens \\
\hline S17 & Bacillus sonorensis & CVC Lumens \\
\hline S18 & Bacillus subtilis & CVC Lumens \\
\hline S19 & Staphylococcus haemolyticus & CVC Tip \\
\hline
\end{tabular}


Supplementary table 5. Biochemical characterisation of bacterial isolates CVCS1 (S1) and CVCS12 (S12) from contaminated CVCs of admitted cardiac patients.

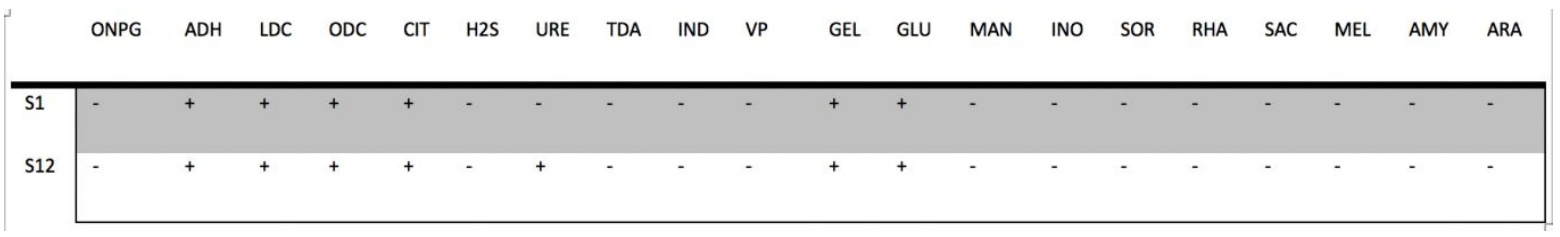

ONPG: test for $\beta$-galactosidase enzyme by hydrolysis of the substrate o-nitrophenyl-b-D-

$$
\text { galactopyranoside }
$$

ADH: decarboxylation of the amino acid arginine by arginine dihydrolase

LDC: decarboxylations of the amino acid lysine by lysine decarboxylase

ODC: decarboxylations of the amino acid ornithine by ornithine decarboxylase

CIT: utilisation of citrate as only carbon source

H2S: production of hydrogen sulfide

URE: test for the enzyme urease

TDA (Tryptophan deaminase): detection of the enzyme tryptophan deaminase: Reagent to put- Ferric Chloride.

IND: Indole Test-production of indole from tryptophan by the enzyme tryptophanase . Reagent- Indole is detected by addition of Kovac's reagent.

VP: the Voges-Proskauer test for the detection of acetoin (acetyl methylcarbinol) produced by fermentation of glucose by bacteria utilizing the butylene glycol pathway

GEL: test for the production of the enzyme gelatinase which liquefies gelatin

GLU: fermentation of glucose (hexose sugar)

MAN: fermentation of mannose (hexose sugar)

INO: fermentation of inositol (cyclic polyalcohol)

SOR: fermentation of sorbitol (alcohol sugar)

RHA: fermentation of rhamnose (methyl pentose sugar)

SAC: fermentation of sucrose (disaccharide)

MEL: fermentation of melibiose (disaccharide)

AMY: fermentation of amygdalin (glycoside)

ARA: fermentation of arabinose (pentose sugar) 


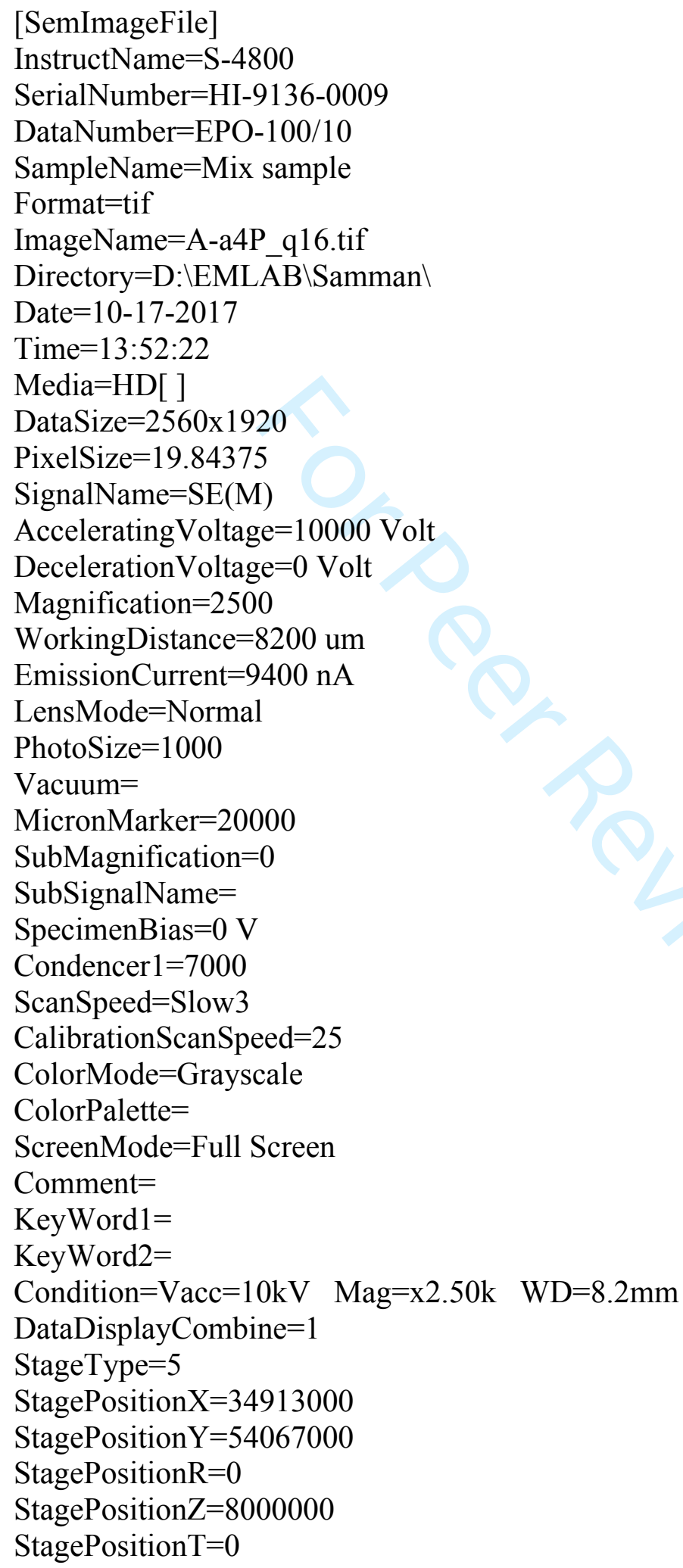

